\title{
Prediction of Fatigue Crack Growth Rate and Stress Intensity Factors Using the Finite Element Method
}

\author{
Yahya Ali Fageehi (iD \\ Mechanical Engineering Department, Jazan University, P. O. Box 114, Jazan 45142, Saudi Arabia \\ Correspondence should be addressed to Yahya Ali Fageehi; yfageehi@jazanu.edu.sa
}

Received 2 September 2021; Accepted 6 January 2022; Published 25 January 2022

Academic Editor: Jean-Michel Bergheau

Copyright (C) 2022 Yahya Ali Fageehi. This is an open access article distributed under the Creative Commons Attribution License, which permits unrestricted use, distribution, and reproduction in any medium, provided the original work is properly cited.

\begin{abstract}
This study investigates crack growth and stress intensity factors via finite element methods in linear elastic fracture mechanics. The procedure involves estimating stress intensity factors (SIFs), crack trajectory, and fatigue life, using two different softwares in both two and three-dimensional analyses. Crack modeling was done in a variety of ways depending on the software. ANSYS Mechanical R19.2 and FRANC2D/L software were used to prognosticate fatigue crack growth, fatigue life, and associated stress intensity factors under plane stress state. Fatigue analysis was governed by Paris's law and crack growth direction by the theory of maximum circumferential stress. The results show that the fatigue growth was attracted to the hole and either changes its direction to reach the hole or floats by the hole and grows as the hole is missed. The findings of the study agree with other experimental and numerical crack propagation studies presented in the literature.
\end{abstract}

\section{Introduction}

Fatigue accounts for one of the more well-known mechanical and structural failures prevalent in industries, including aerospace and automotive components. Structural failure impairs components and poses health risks to people. Consequently, in obtaining an accurate solution, the study of such failures may involve significant complexity in evaluating a component's expected service life, which is the sum of the number of loading cycles needed to initiate a fatigue crack and the number of cycles needed to propagate to the critical size $[1,2]$. The assessment of fatigue crack growth includes identifying the direction of crack, equivalent stress intensity factor range $(\Delta K e q)$, and crack growth rate per cycle number $(d a / d N)$. It is possible to ascertain the failure of the crack members subjected to static or fatigue loading by comparing the $\Delta K e q$ value to a certain characteristic of each material (known as fracture toughness or threshold stress intensity factor, respectively). Crack initiation and propagation should be associated to SIFs in a complicated state [3-6]. To address fatigue crack propagation, the linear elastic fracture mechanics (LEFM) method was developed. The LEFM techniques have been mostly accepted for long cracks with small-scale yielding characteristics at the crack front, i.e., the Paris regime $[7,8]$. The stress intensity factors (SIFs) under the concept of LEFM were used in identifying the status of crack propagation, i.e., whether the crack propagates or not. Internal crack propagation is important in engineering practice because it has a significant effect on the performance and stability of structural engineering. As a result, crack propagation path prediction is essential for engineering structural reliability. Preliminary investigations are necessary in estimating fatigue in aerospace, manufacturing, and aviation industry, this being cost-prohibitive, an alternative, but accurate estimation is necessary in predicting crack growth, orientation, and fatigue life in static and dynamic loads [9-11]. The finite element method (FEM) is a powerful computative approach in predicting the performance of complicated geometries and structures in engineering practice. The remeshing technique allows FEM to model fatigue crack propagation and simulates irregular crack growth by piecemeal mesh regeneration [12-15]. 


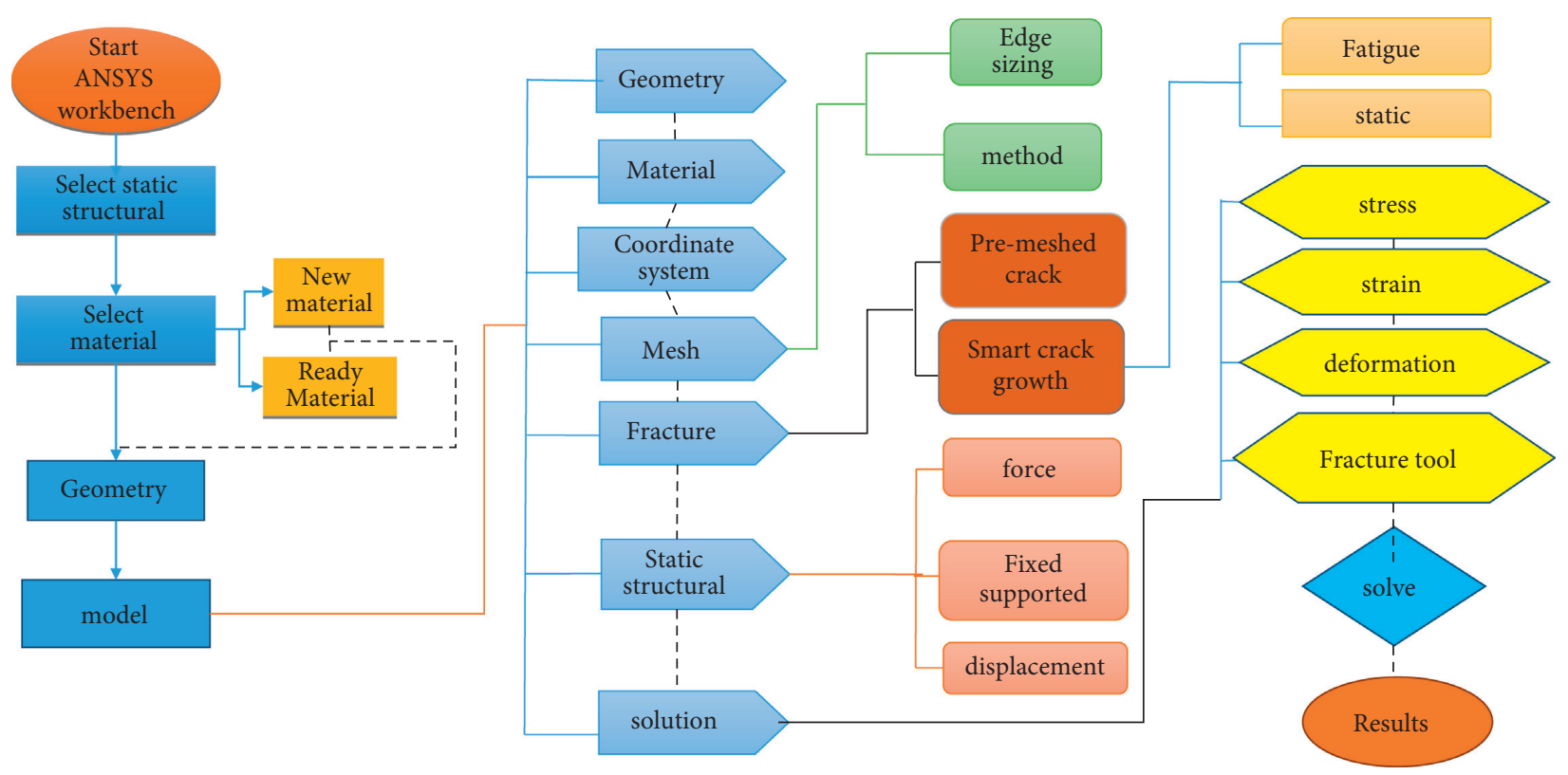

FIgURE 1: ANSYS flowchart for SMART crack growth.

Several approaches were employed in simulating fatigue crack growth: discrete elements method (DEM) [16-18], elements-free Galerkin (EFG) method [19], XFEM [20-23], cohesive elements method [24, 25], and phase-field method [26].

Incorporating a simulation methodology involving two and three-dimensional numerical analyses combining FRANC2D/L and ANSYS Mechanical R19.2 is an efficient way to reduce laboratory effort, time, and costs. Various computational techniques in terms of simulation for simple and complicated geometries in $2 \mathrm{D}$ and $3 \mathrm{D}$ have been reported in many fatigue crack problems [9, 27-36].

This work compares the fatigue crack growth under constant amplitude load between two softwares, ANSYS Mechanical R19.2 and FRANC2D/L, as an alternative tool for modeling fatigue crack growth problems in mixed-mode loads. Four different configurations of the modified compact tension were simulated in both softwares. The crack growth trajectory, SIFs, stresses distribution, and fatigue life cycles were predicted using both softwares, and the outcome from other researchers validated the results.

Fatigue assessment of materials can be mostly illustrated by three approaches: the fracture mechanics method proposed by Paris and Erdogan [37], the method of strain-life independently obtained by Coffin [38], and the stress-life method proposed by Wöhler [39]. The first method was employed (in the present work) in estimating fatigue life, and the crack tip was characterized independently by the SIFs.

\section{Materials and Methods}

2.1. Mixed-Mode Fatigue Life Evaluation Procedure Using ANSYS Mechanical R19.2. ANSYS models three types of cracks: arbitrary, semielliptical, and premeshed. The latest feature presented in ANSYS Mechanical R19.2 is the Separating Morphing and Adaptive Remeshing Technology (SMART), and the crack growth in which mesh-based is a tetrahedron. The premeshed method requires the crack front used by the SMART crack growth analysis tool, where the stress intensity factor is the criterion of failure. Rendered node sets are distributed in the front, top, and bottom of the crack. Surrounding mesh at the crack tip is refined through the sphere of the influence process around the geometric sides that passes across the width. The geometric regions to be described are crack tip, top, and bottom surfaces of crack. Subsequently, these regions are linked with a node set for analysis. ANSYS Mechanical R19.2 software considers mixed-mode loading where the maximum circumferential stress criterion is implemented. The following are the formulas for the direction of crack propagation in ANSYS $[40,41]$ :

$$
\theta=\cos ^{-1}\left(\frac{3 K_{\mathrm{II}}^{2}+K_{I} \sqrt{K_{I}^{2}+8 K_{\mathrm{II}}^{2}}}{K_{I}^{2}+9 K_{\mathrm{II}}^{2}}\right),
$$

where $K_{I}=\operatorname{Max} K_{I}$ during cyclic loading and $K_{\mathrm{II}}=\operatorname{Max} K_{\mathrm{II}}$ during cyclic loading.

In ANSYS Mechanical R19.2, by using XFEM, crack growth simulation is restricted to region II, and typical fatigue crack growth graph is represented as

$$
\frac{\mathrm{d} a}{\mathrm{~d} N}=C\left(\Delta K_{\mathrm{eq}}\right)^{m}
$$

where $a$ is the length of the crack, $N$ is the number of cycles, $C$ is the Paris constant, and $m$ is the Paris exponent. Both $C$ and $m$ are dependent strongly on the cyclic hardening 


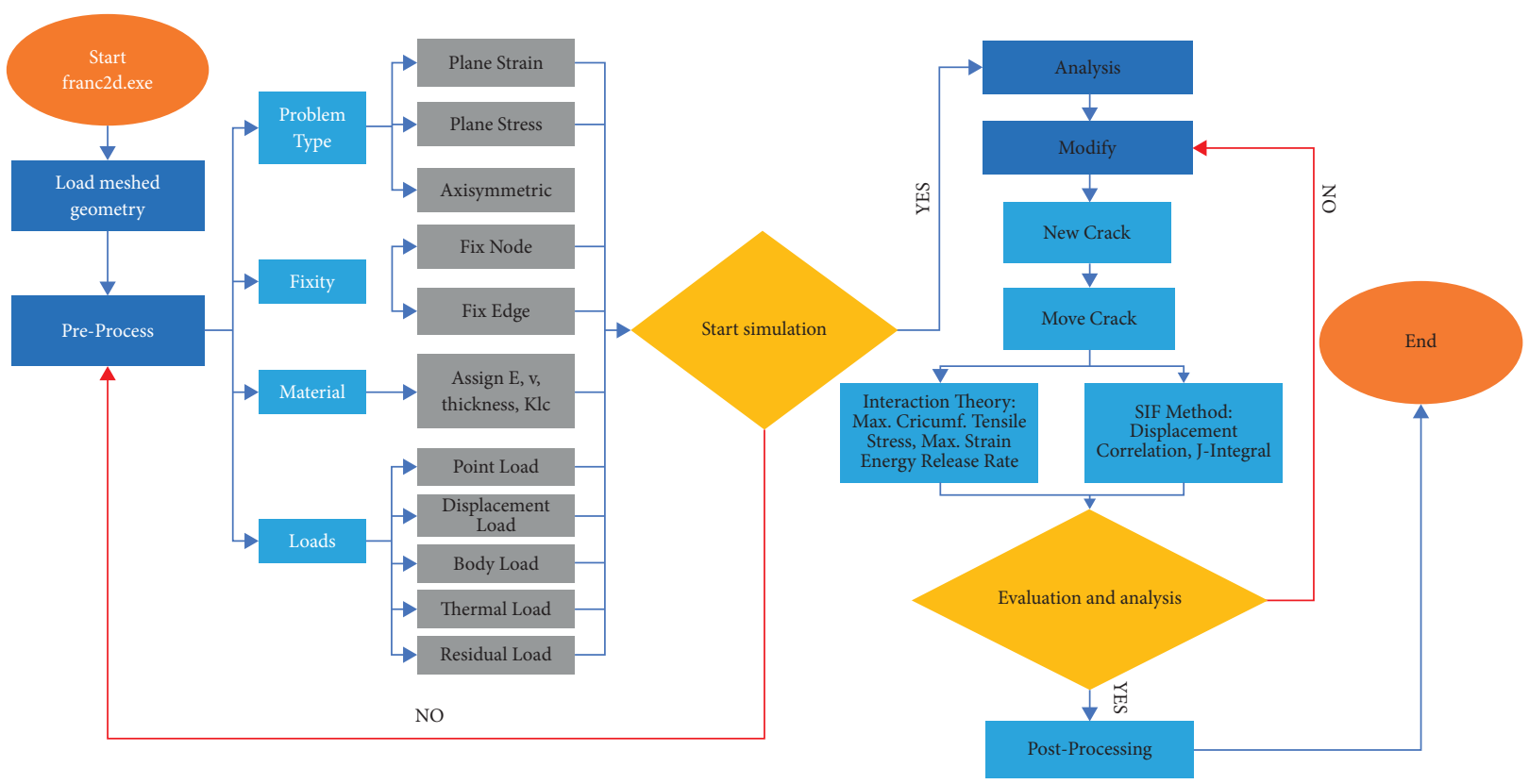

FIGURE 2: FRANC2D/L procedure for crack growth.

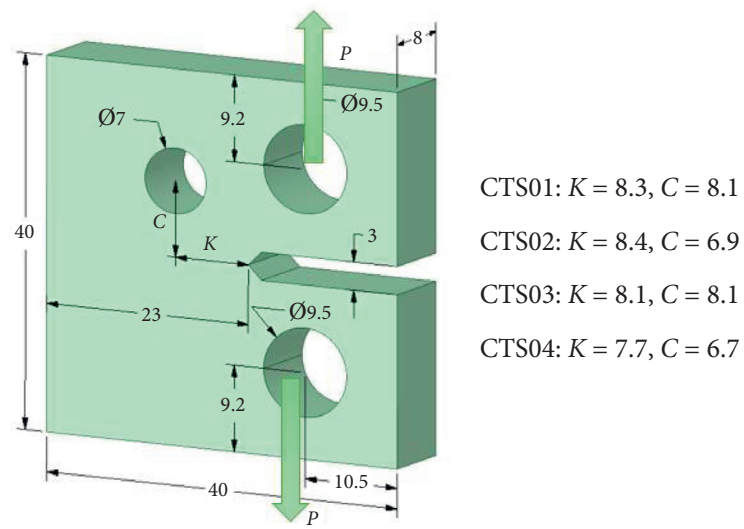

FIgure 3: Geometrical details of the modified compact tension specimen (MCTS) (all dimensions in mm).

exponent and mechanical properties [42], and they are obtained experimentally. Several authors $[43,44]$ identified a very consistent empirical relationship between Paris' law parameters, which was supported by experimental results, such as $[45,46]$.

From equation (2), the number of fatigue life cycles for crack increment is

$$
\int_{0}^{\Delta a} \frac{\mathrm{d} a}{C\left(\Delta K_{\mathrm{eq}}\right)^{m}}=\int_{0}^{\Delta N} \mathrm{~d} N=\Delta N .
$$
[47]

The equivalent range for SIFs formula is represented as

$$
\Delta K_{\mathrm{eq}}=\frac{1}{2} \cos \frac{\theta}{2}\left[\left(\Delta K_{I}(1+\cos \theta)\right)-3 \Delta K_{\mathrm{II}} \sin \theta\right],
$$

where $\Delta K_{\mathrm{I}}$ represents the SIFs range in mode I loading and $\Delta K_{\mathrm{II}}$ represents the SIFs in mode II loading. ANSYS flowchart is shown in Figure 1.
Table 1: Properties of the considered material.

\begin{tabular}{lc}
\hline Property & Value in metric unit \\
\hline Elasticity modulus, $E$ & $205 \mathrm{GPa}$ \\
Poisson's ratio, $v$ & 0.29 \\
Yield strength, $\sigma_{y}$ & $285 \mathrm{MPa}$ \\
Ultimate strength, $\sigma_{u}$ & $491 \mathrm{MPa}$ \\
Paris' law coefficient, $C$ & $8.59 \times 10-14 \mathrm{~mm} /\left(\right.$ cycle $\left.\mathrm{MPa} \mathrm{mm}^{0.5}\right)$ \\
Paris law exponent, $m$ & 4.26 \\
\hline
\end{tabular}

2.2. FRANC2D/L Procedure. The Cornell Fracture Mechanics Group at Cornell University developed the free twodimensional fracture analysis software FRANC2D/L, which was funded by the US National Science Foundation, NASA, the US Navy, and other agencies [19]. The FRANC2D/L analysis is carried out in two stages, with CASCA which is used as a mesh generator with different types of mesh and associated with FRANC2D/L. In the second part, the boundary constraints, problem characteristics, stress 


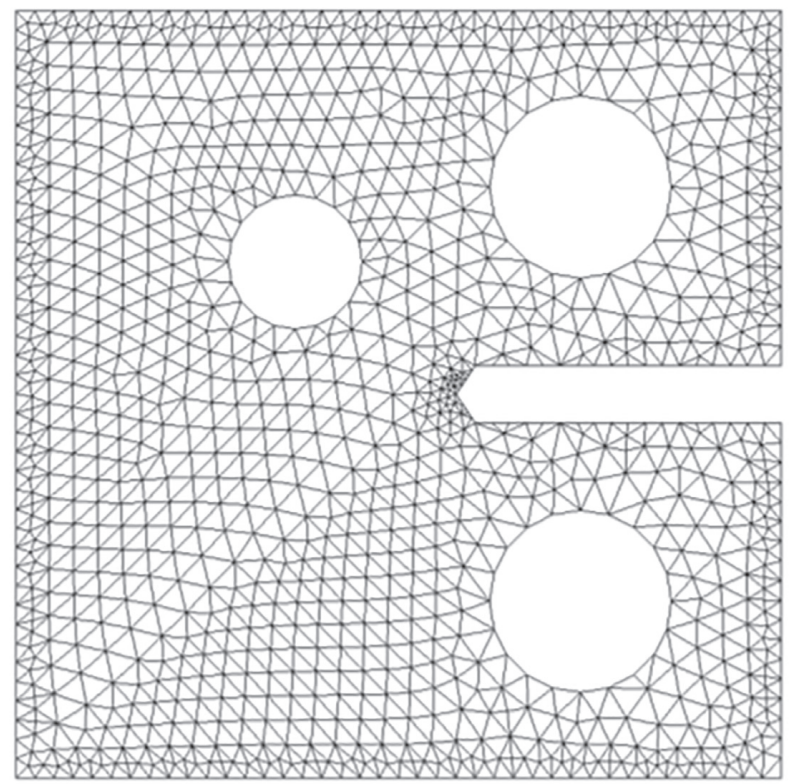

(a)

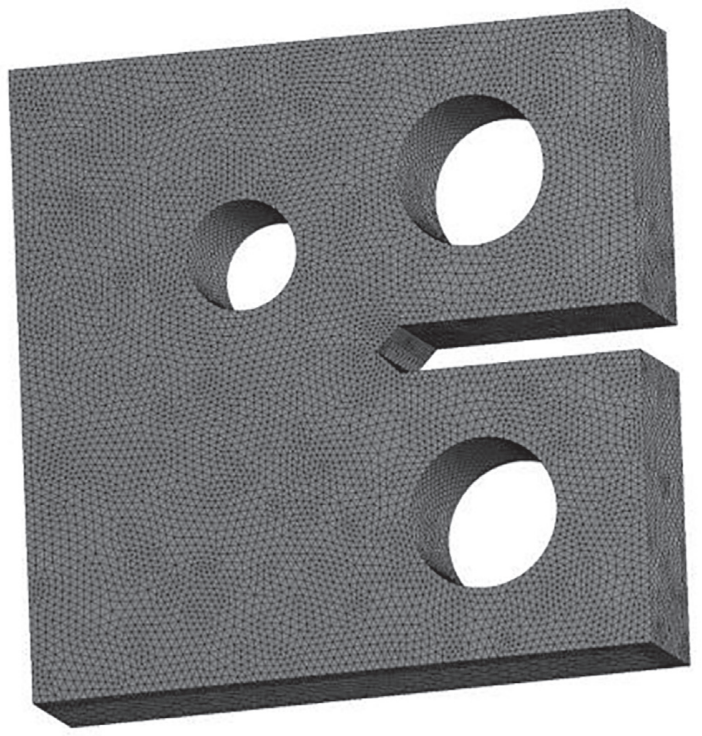

(b)

FIgURE 4: Initial meshes of CT01. (a) FRANC2D/L and (b) ANSYS Mechanical R19.2.

computation, input crack singularity, crack growth, and problem outcomes were determined [48, 49]. SIFs were computed using three approaches in FRANC2D/L: method of displacement correlation, method of modified crack closure integral, and method of J-integral. The crack orientation was estimated via maximum circumferential stress criterion, while fatigue crack growth rate was calculated based on Paris law equation with the same procedure used in ANSYS as represented in equations (1) and (2), respectively. The step-by-step procedure of the FRANCD2D/L software is shown in Figure 2.

\section{Results and Discussion}

3.1. Modified Compact Tension Specimens (MCTS). Figure 3 shows the modified CT specimen's geometrical dimensions in two and three-dimensional representations. According to this figure, the hole's diameter is $7 \mathrm{~mm}$ from the crack's initiation position, which is located on horizontal and vertical distances $K$ and $C$; for isotropic and linear elastic material at 0.1 load ratio, the test was performed under fatigue load. A total of four specimens were simulated in both programs. The material properties are given in Table 1, as well as for the initial mesh for the first specimen, CT01 in both softwares is shown in Figure 4. Table 2 provides a total number of nodes and elements for every specimen with different values in two softwares. The size of the mesh element was set as $1 \mathrm{~mm}$.

Simulation from FRAN2D/L and ANSYS was juxtaposed with experimental [50] and numerical fatigue crack growth paths [32] using the boundary elements method (BEM) with BemCracker 2D software and FEM with Quebra2D software for CT01, CT02, CT03, and CT04 as shown in Figures 5-8, respectively. The crack pathways in this work in all cases using FRANC2D/L and ANSYS align with the experimental and numerical results of $[32,50]$. Moreover, the growth of the fatigue crack was consistently captivated by the hole; it curves and grows into the hole (sinks in the hole behavior), as shown in Figures 6 and 8, or deflect and propagate after missing the hole (missing the hole's behavior), as shown in Figures 5 and 7 . The fatigue life cycles in individual structures significantly vary, depending on crack path, though hole location is only slightly differentiated. The fatigue crack was still captivated to the hole, according to the simulations, so it could curve its path and grow toward the hole or merely deflect and propagate.

Maximum and minimum principal stresses of the four specimens are compared in both programs as shown in Figures 9-12. There is a small percentage of error between the values obtained between the software due to the number of steps used in both softwares and the numerical procedure of the programs. For CT01, the higher value of the maximum principal stress in FRANC2D was 310.2 MPa, whereas it was $355 \mathrm{MPa}$ in ANSYS. For CT02, the higher value of the maximum principal stress in FRANC2D was $90.3 \mathrm{MPa}$, whereas it was 123.4 MPa in ANSYS. For CT03, the higher value of the maximum principal stress in FRANC2D was 250.36 MPa, whereas it was 274.4 MPa in ANSYS. For CT04, the higher value of the maximum principal stress in FRANC2D was $56 \mathrm{MPa}$, whereas it was $72 \mathrm{MPa}$ in ANSYS.

The predicted values of stress intensity factors for mode I and mode II ( $K_{I}$ and $\left.K_{I I}\right)$ associated with the crack length for CT01, CT02, CT03, and CT03 are shown in Figures 13-16, respectively.

It has worth noting that when there is a hole in the crack path, $K_{I}$ decreases to a certain amount while $K_{I I}$ increases. This is visible in the crack path's trajectory; when the crack continues in a straight line, $K_{I}$ increases, but as the direction 
TABLE 2: Number of nodes and elements of the specimens in FRANC2D/L and ANSYS APDL 19.2.

\begin{tabular}{lcccc}
\hline MCTS & \multicolumn{2}{c}{ FRANC2D/L } & \multicolumn{2}{c}{ ANSYS Mechanical } \\
& Nodes & Elements & Nodes & Elements \\
\hline CT01 & 4606 & 2172 & 491691 & 326808 \\
CT02 & 4594 & 2166 & 1989912 & 1307107 \\
CT03 & 4598 & 2168 & 1819895 & 1193704 \\
CT04 & 4634 & 2186 & 1848501 & 1214092 \\
\hline
\end{tabular}

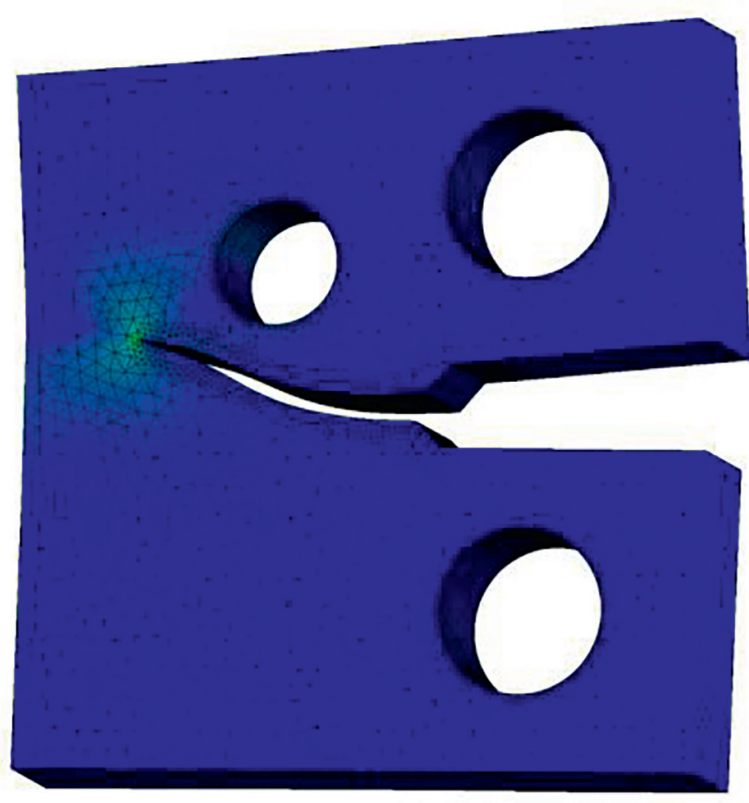

(a)

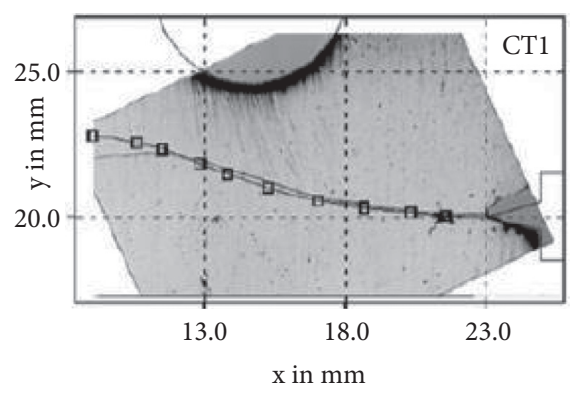

(c)

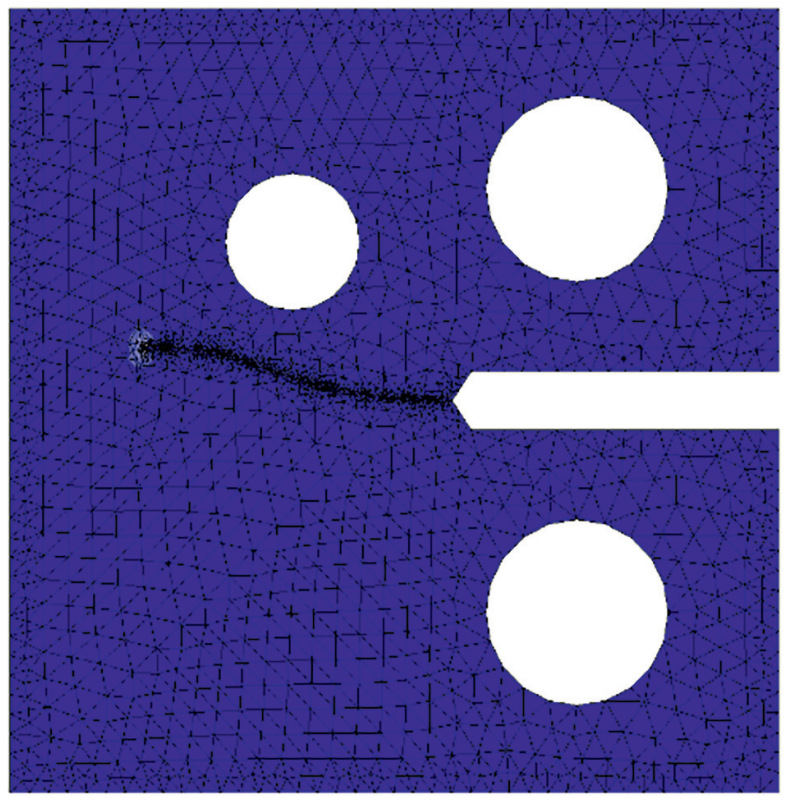

(b)

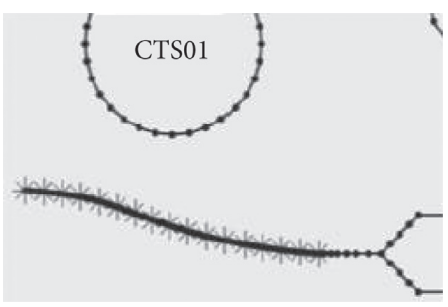

(d)

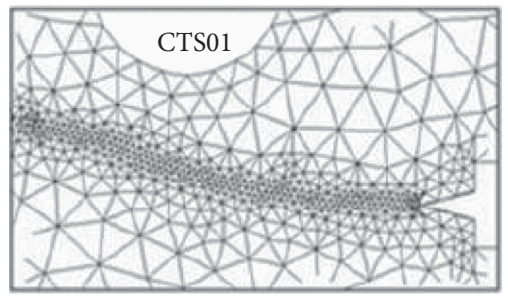

(e)

Figure 5: The predicted crack path of CTS01. (a) ANSYS results, (b) FRANC2D/L, (c) experimental and numerical outcome of [50], (d) BemCracker2D software [32], and (e) Quebra2D software [32].

changes, $K_{I I}$ increases. The previous figures for the stress intensity factors demonstrate that all simulated specimens in FRANC2D/L and ANSYS have nearly the same values of $K_{I}$ and $K_{I I}$ over the crack growth duration. These minor variations in the results are influenced by the number of steps used in each program as well as the numerical approach 


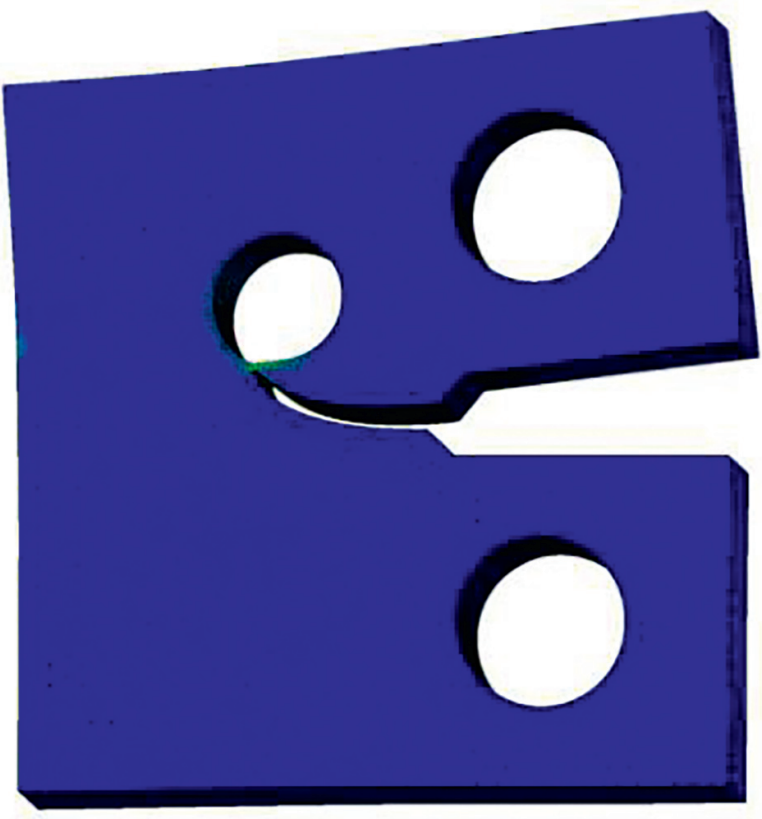

(a)

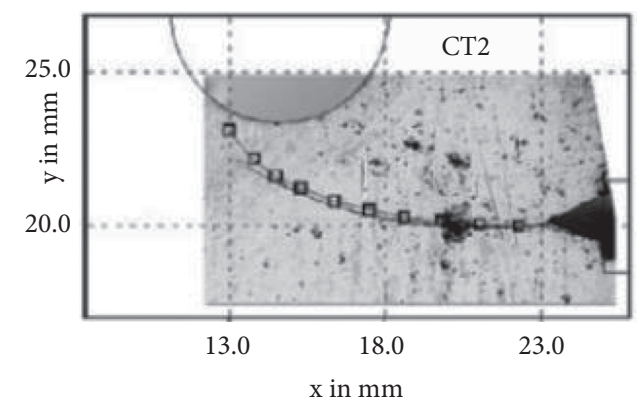

(c)

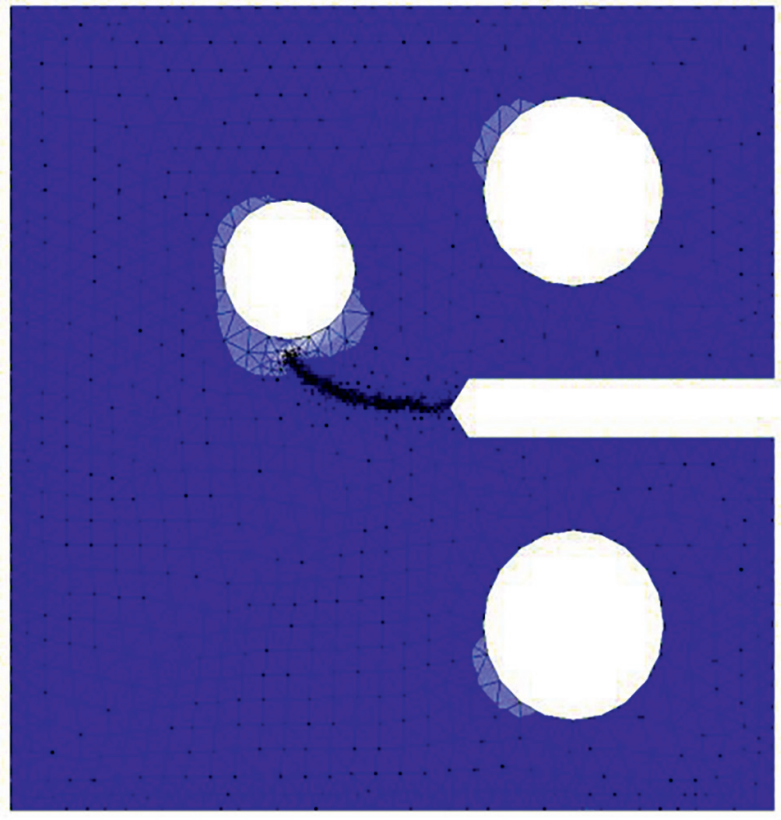

(b)

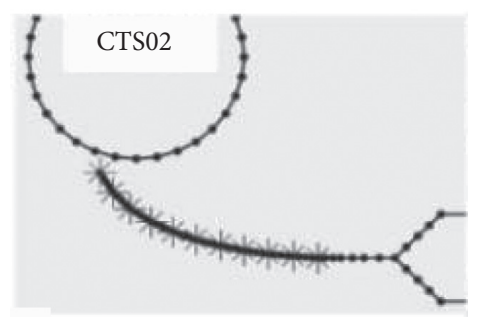

(d)

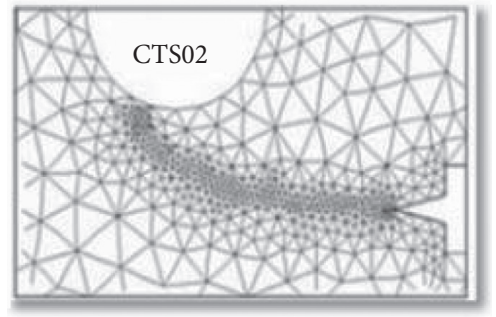

(e)

Figure 6: The predicted crack path of CTS02. (a) ANSYS results, (b) FRANC2D/L, (c) experimental and numerical results of [50], (d) BemCracker2D software [32], and (e) Quebra2D software [32].

used. The number of steps used in ANSYS for specimen simulation ranges from 11 to 20 , with the number of increments controlled by the software. In FRANC2D/L, the steps range from 32 to 92 with $0.1-0.13$ increment.

Figures 17-20 show comparisons of FRANC2D/L and ANSYS fatigue life simulations with experimental outcomes [32] for CT01, CT02, CT03, and CT04 MCTS geometries, respectively. The simulated fatigue crack growth life using FRANC2D/L and ANSYS agrees very well with the experimental results by Gomes and Miranda [32]. In addition, the current research results were far more precise in predicting fatigue life compared to the numerical findings obtained with [32] using the two softwares, VIDA and BemCracker2D. The results of this analysis are closely associated with Quera2D rather than BemCracker2D, as shown in these figures. These findings further demonstrate the influence of the hole position on the fatigue life of the specimens. 


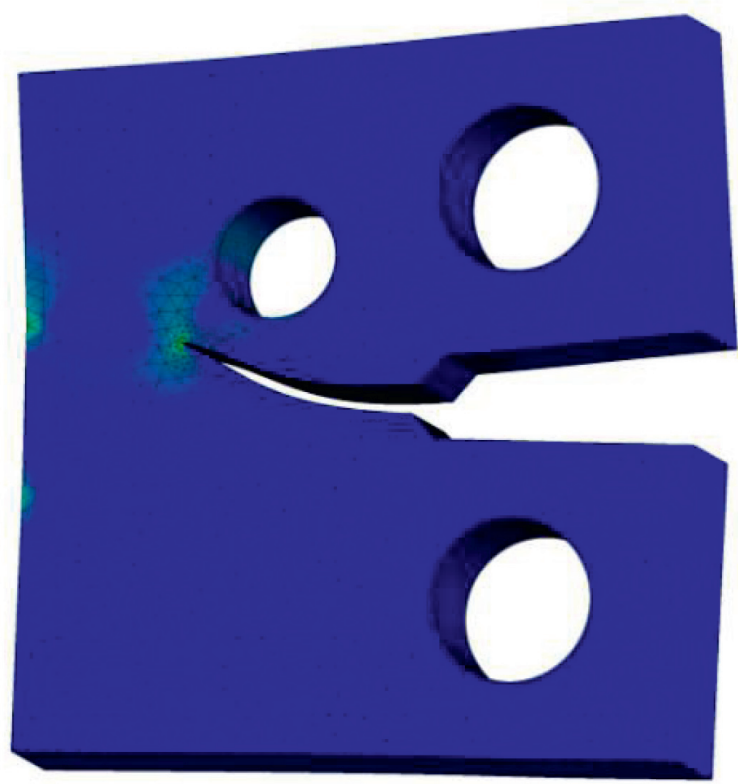

(a)

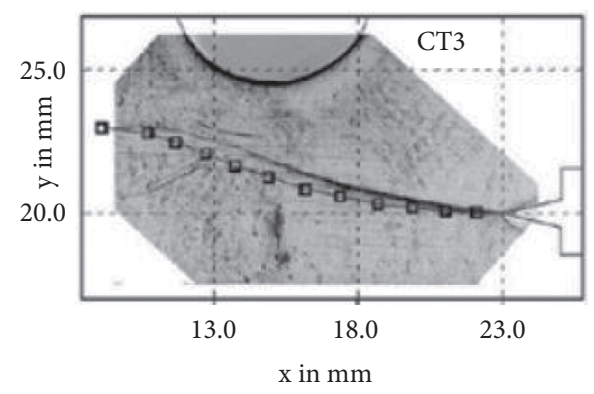

(c)

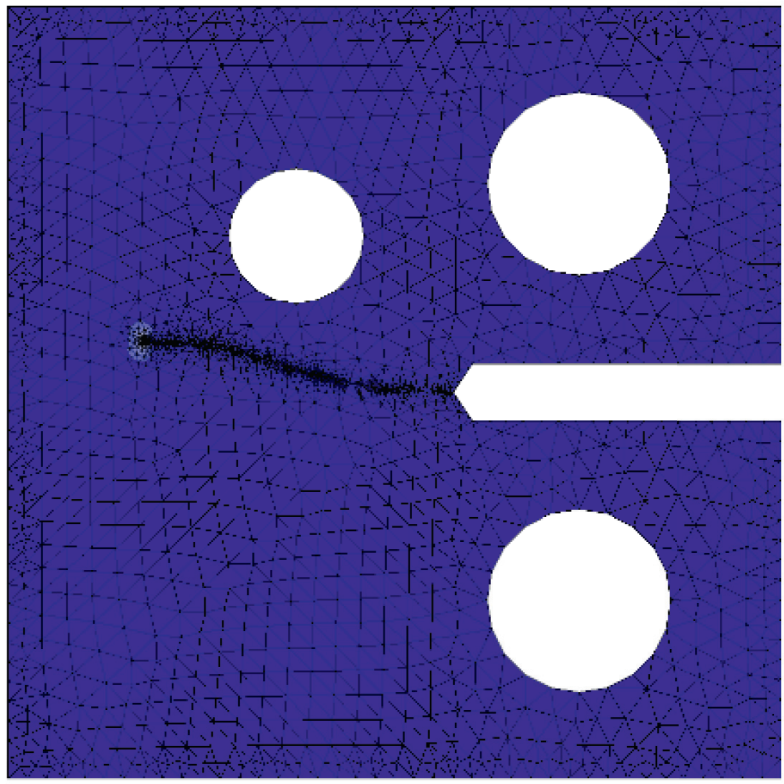

(b)

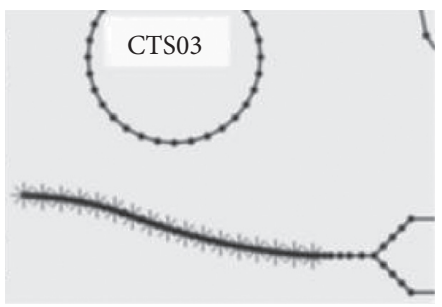

(d)

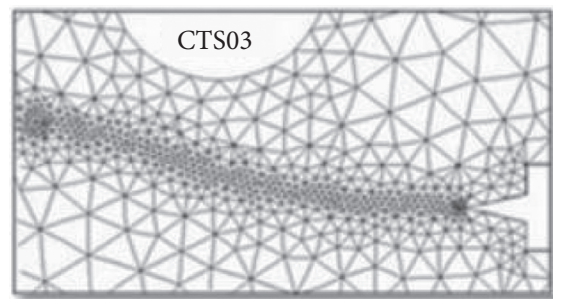

(e)

Figure 7: The predicted crack path of CTS03. (a) ANSYS results, (b) FRANC2D/L, (c) experimental and numerical outcome of [50], (d) BemCracker2D software [32], and (e) Quebra2D software [32]. 


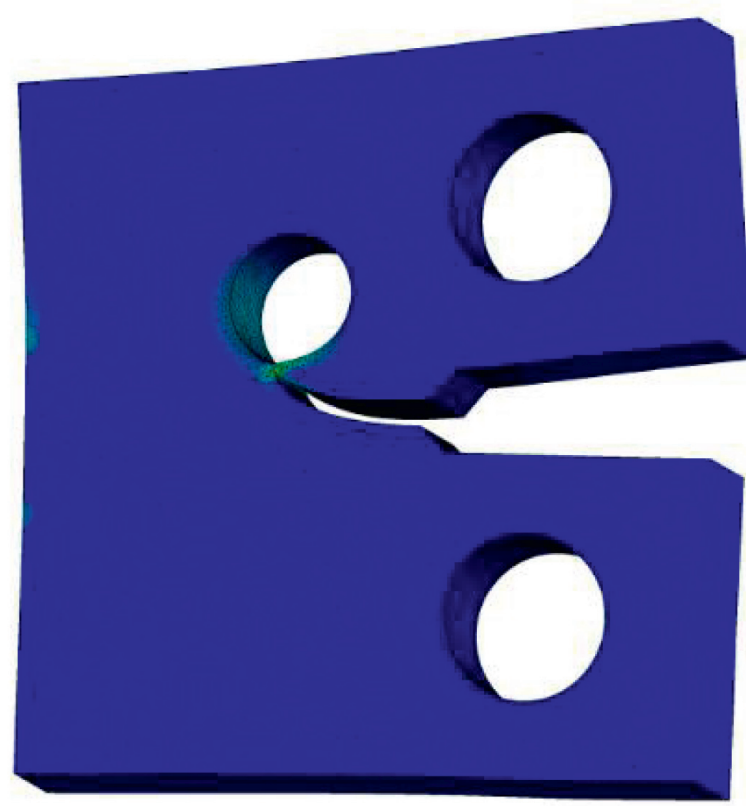

(a)

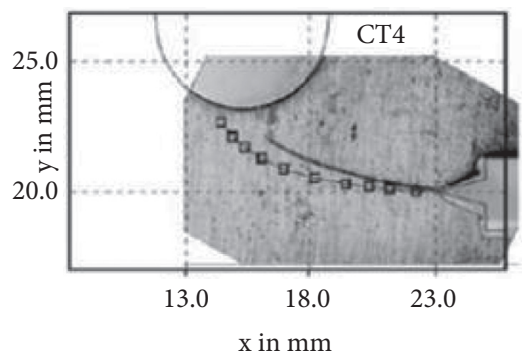

(c)

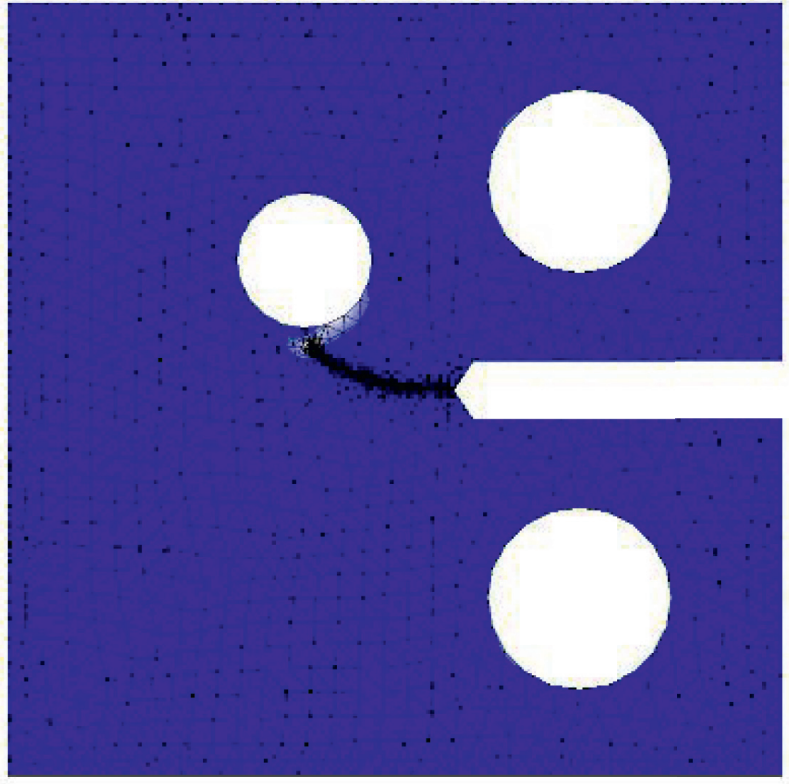

(b)

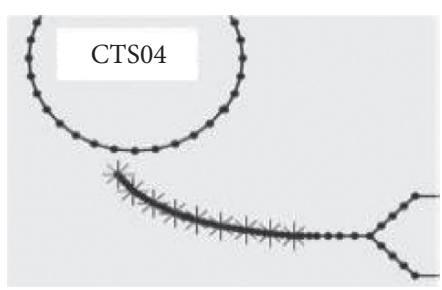

(d)

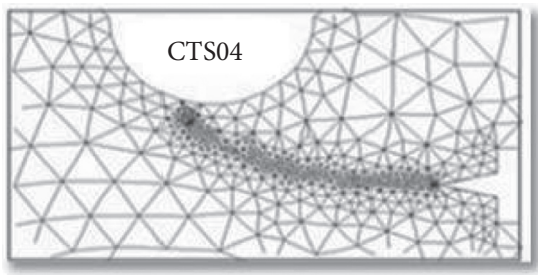

(e)

Figure 8: The predicted crack path of CTS04. (a) ANSYS results, (b) FRANC2D/L, (c) experimental and numerical outcome of [50], (d) BemCracker2D software [32], and (e) Quebra2D software [32]. 

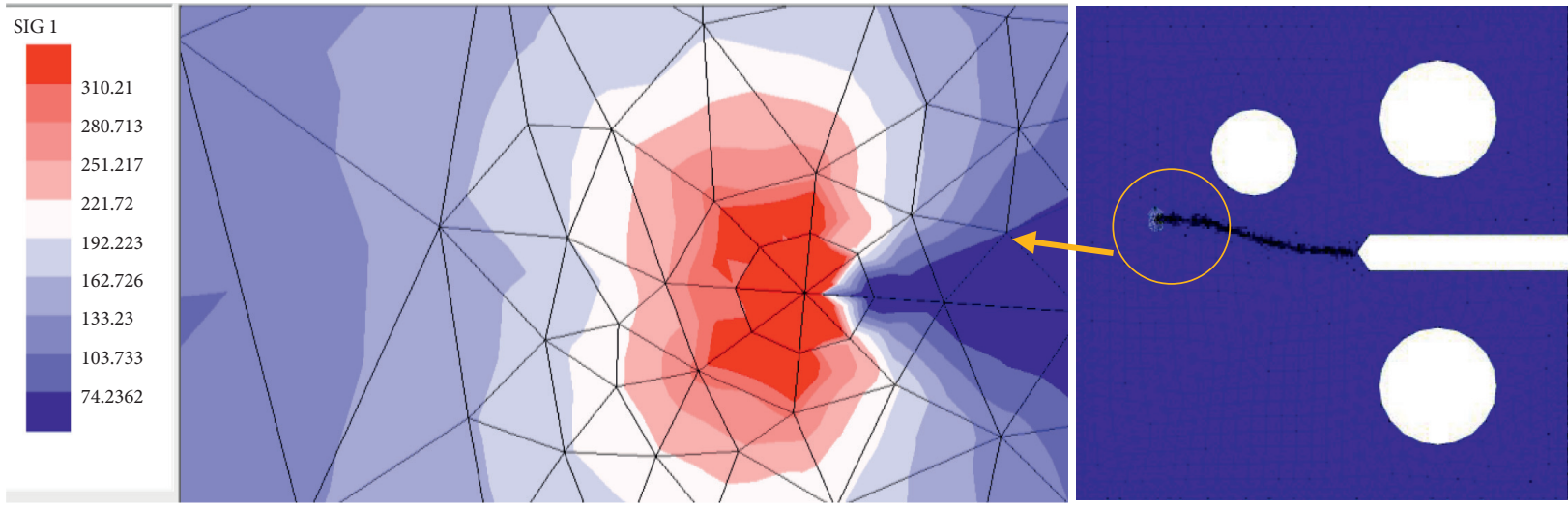

(a)
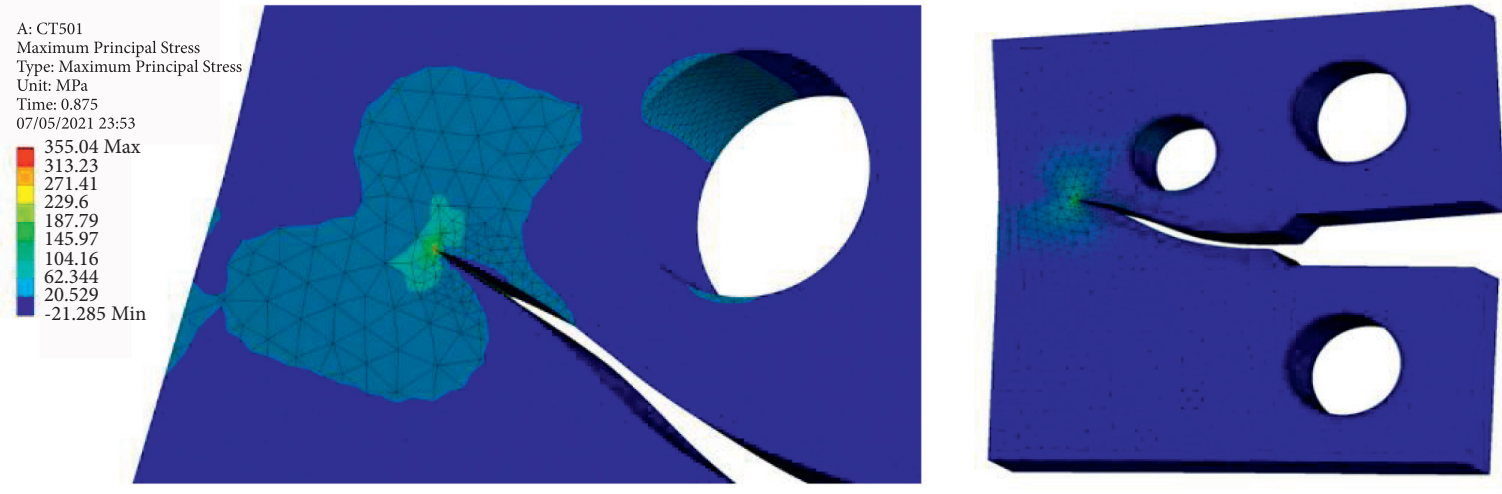

(b)
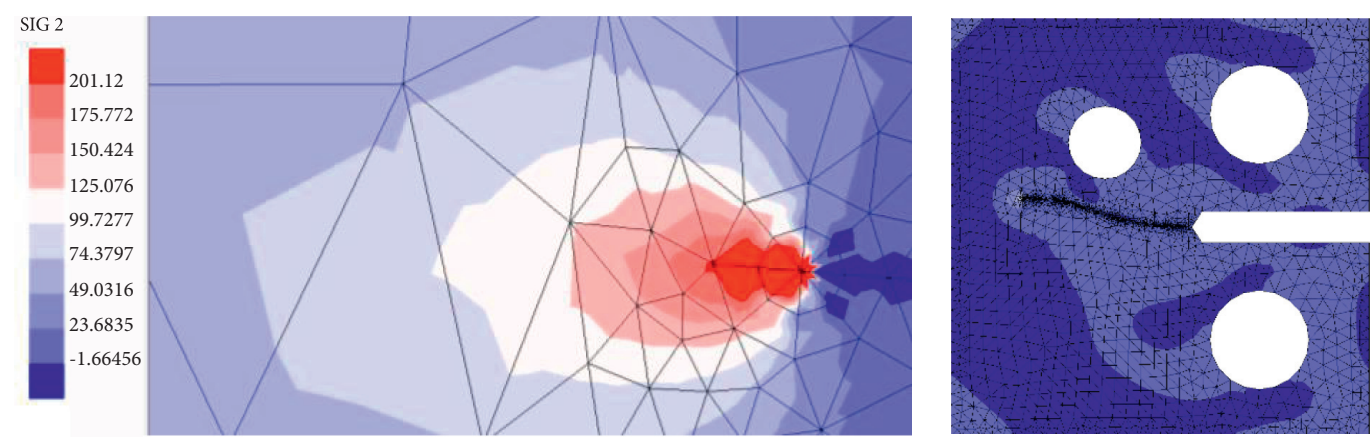

(c)
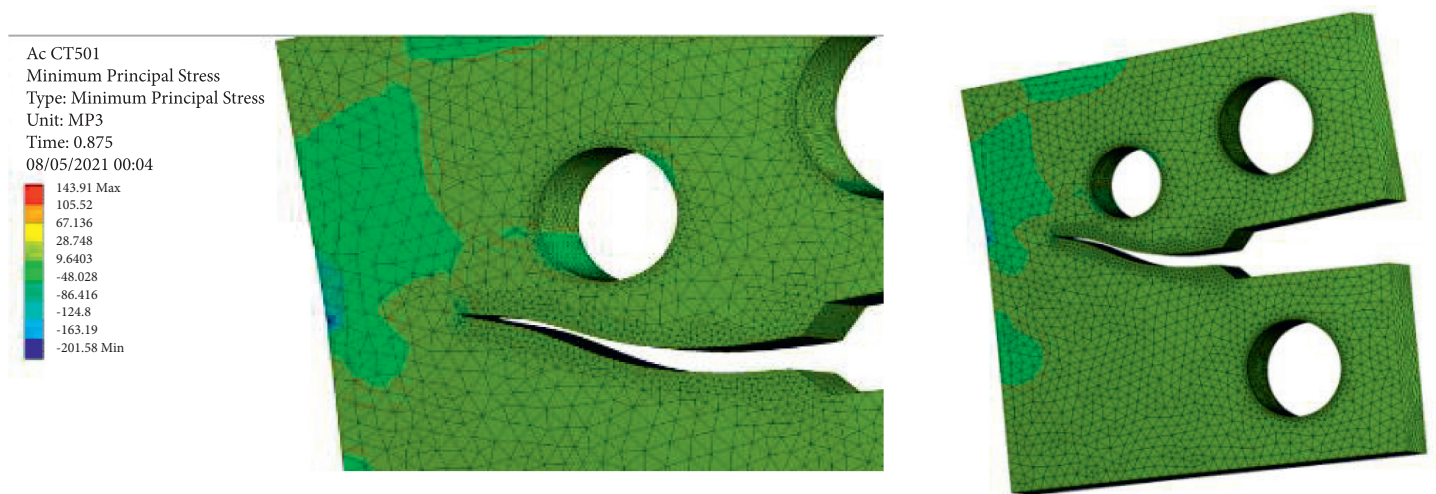

(d)

FIgUre 9: For CT01 specimen, (a) FRANC2D/L, maximum principal stress, (b) ANSYS, maximum principal stress, (c) FRANC2D/L, minimum principal stress, and (d) ANSYS, minimum principal stress. 

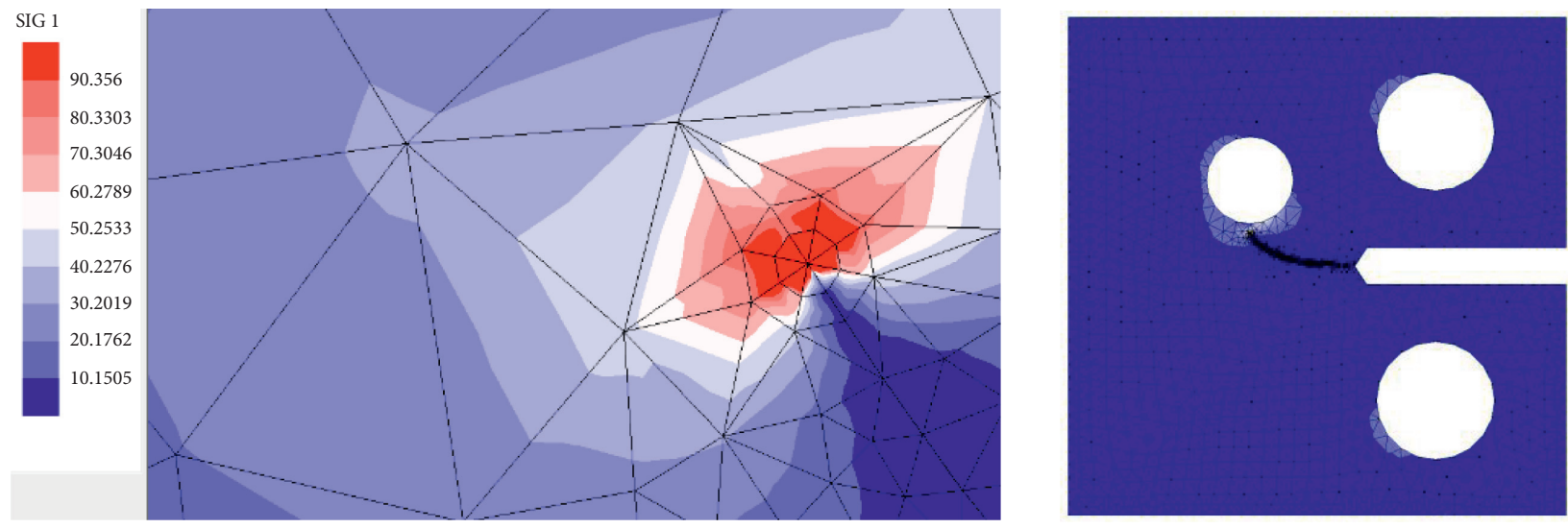

(a)
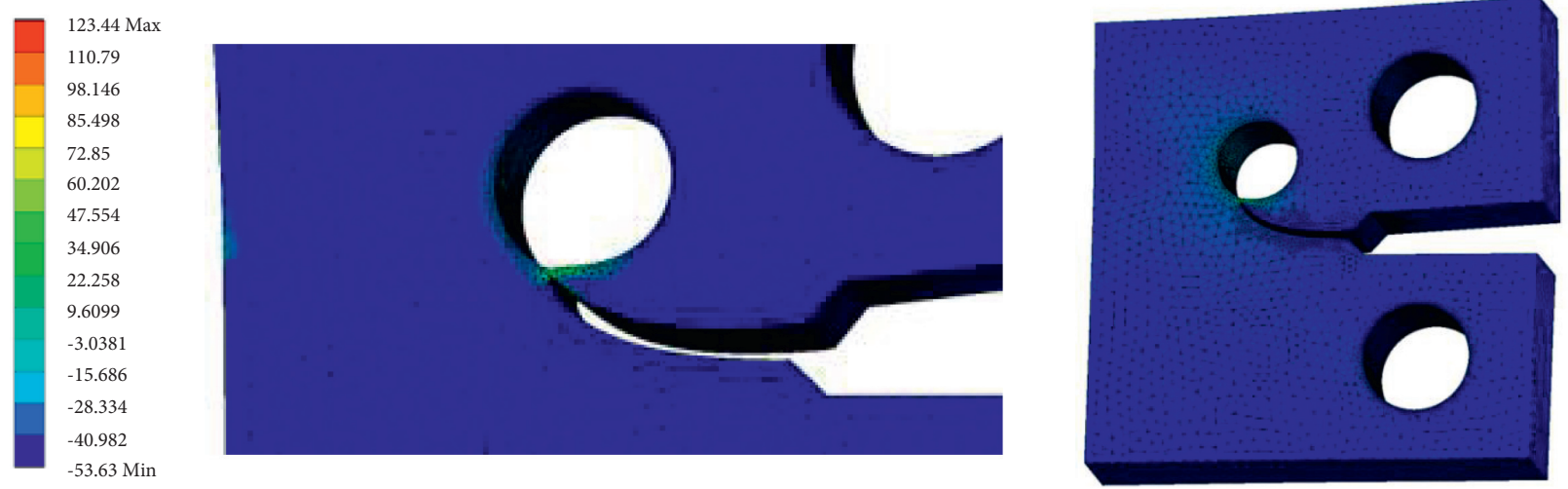

(b)
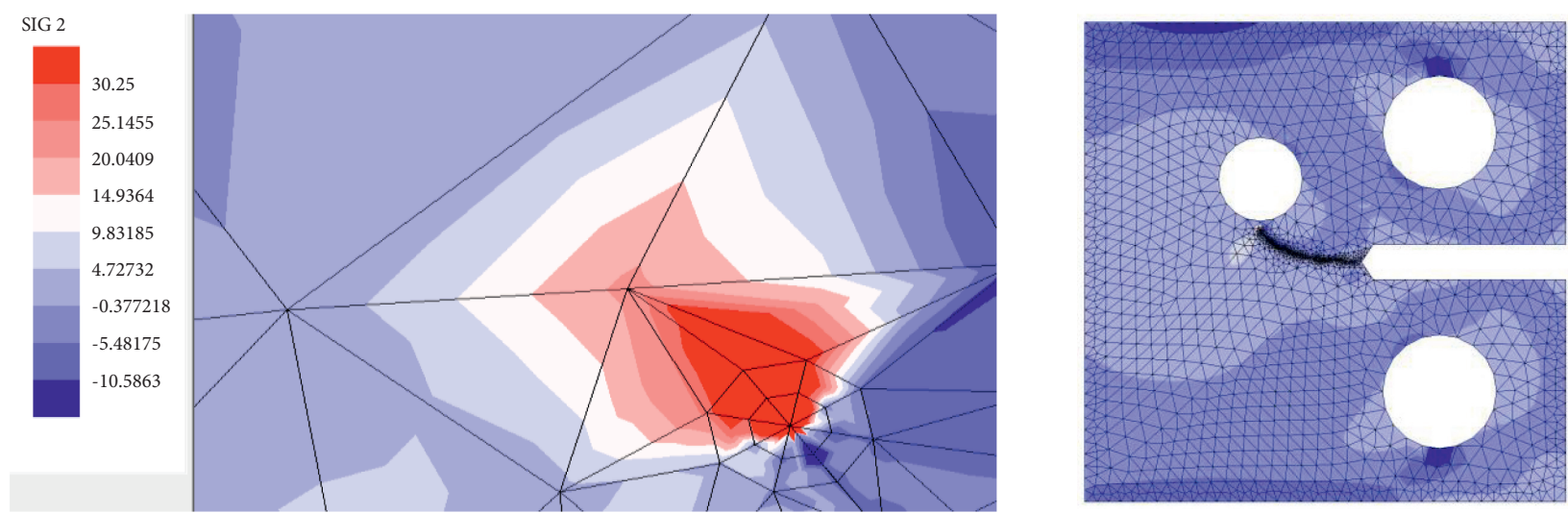

(c)
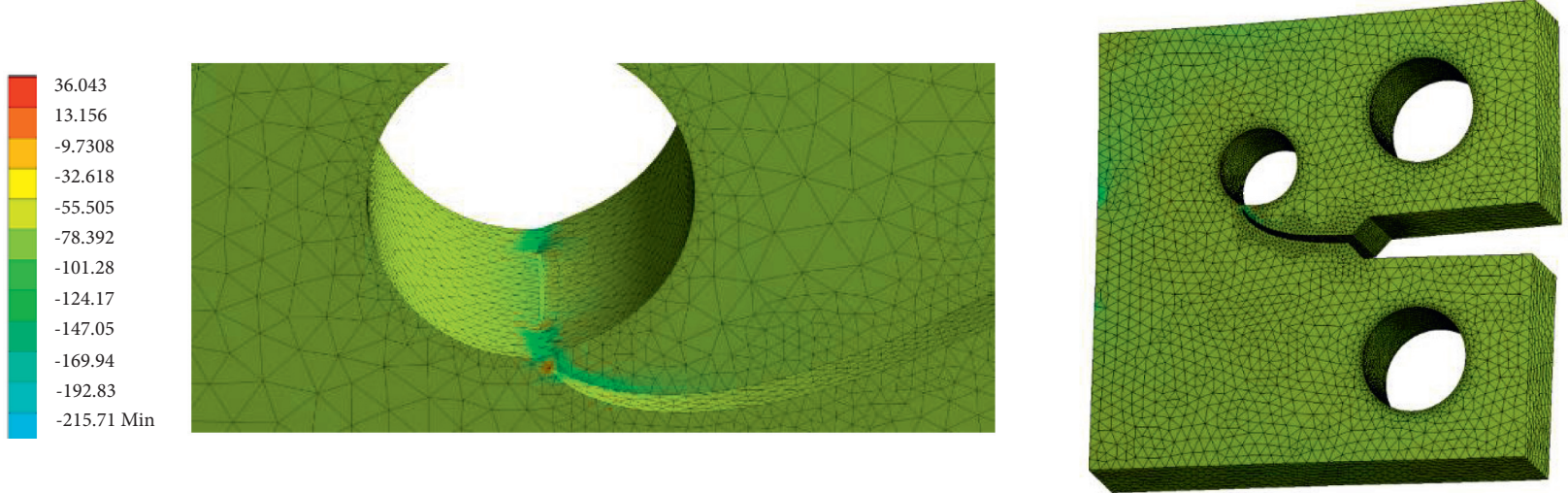

(d)

FIgUre 10: For CT02 specimen, (a) FRANC2D/L, maximum principal stress, (b) ANSYS, maximum principal stress, (c) FRANC2D/L, minimum principal stress, and (d) ANSYS, minimum principal stress. 

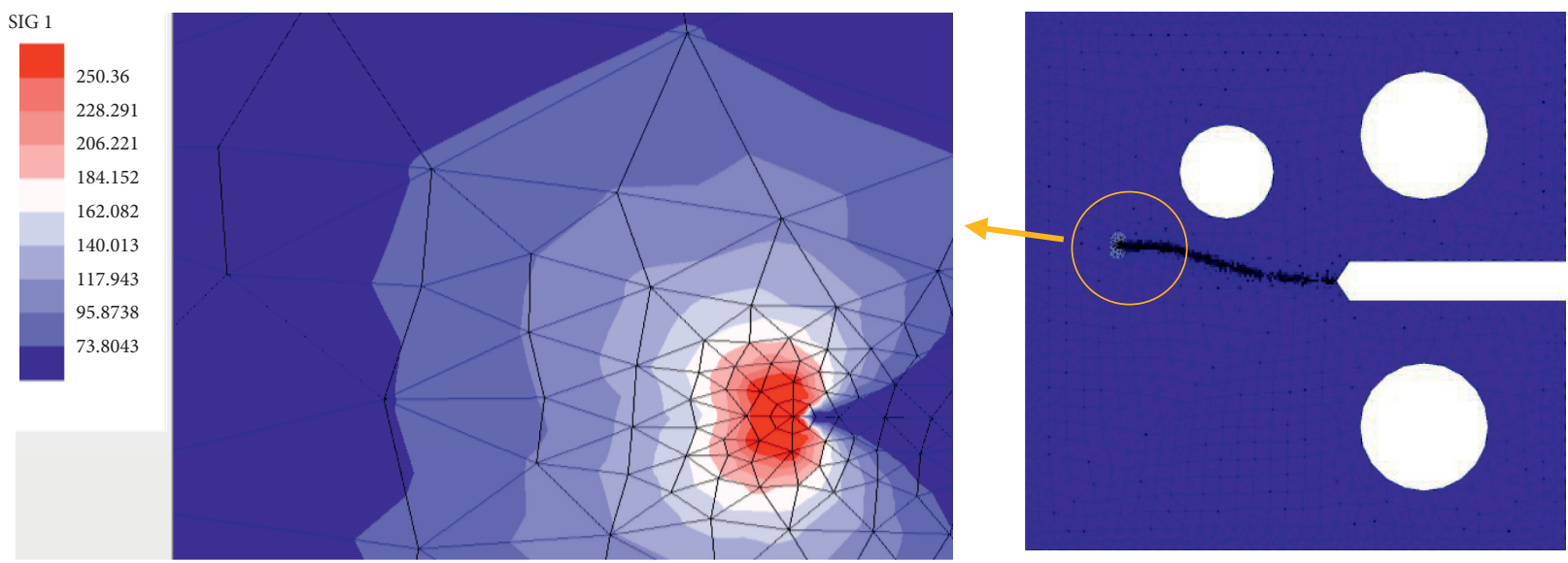

(a)
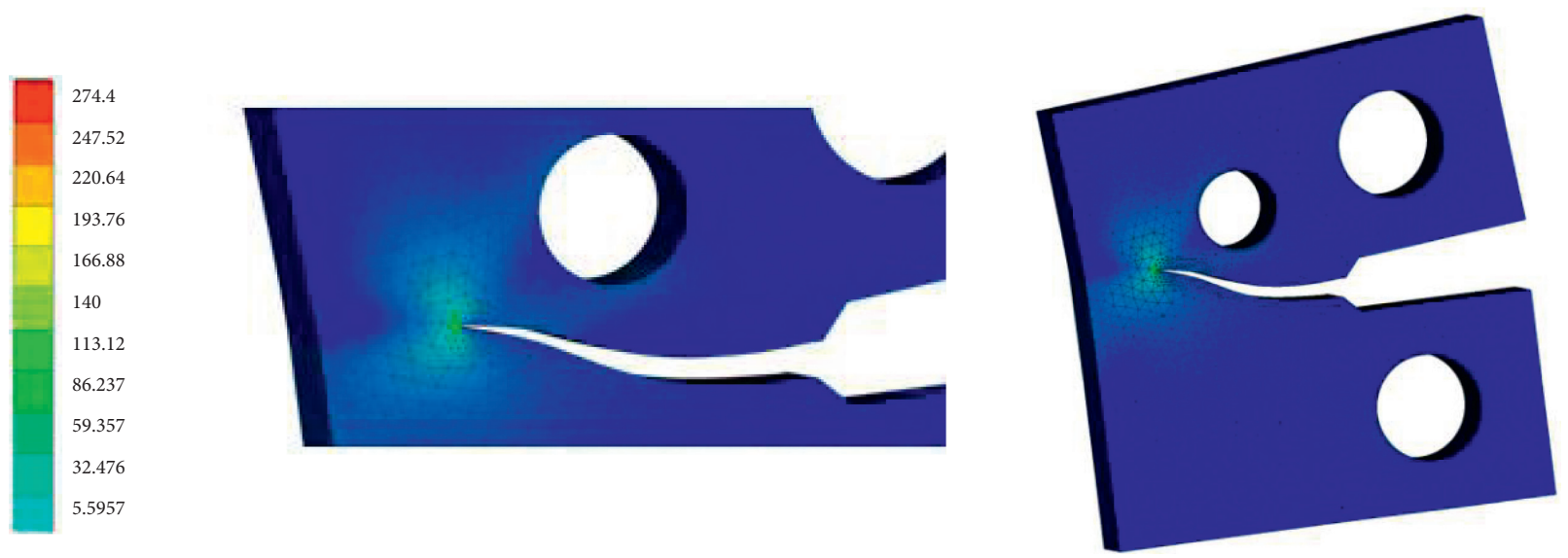

(b)
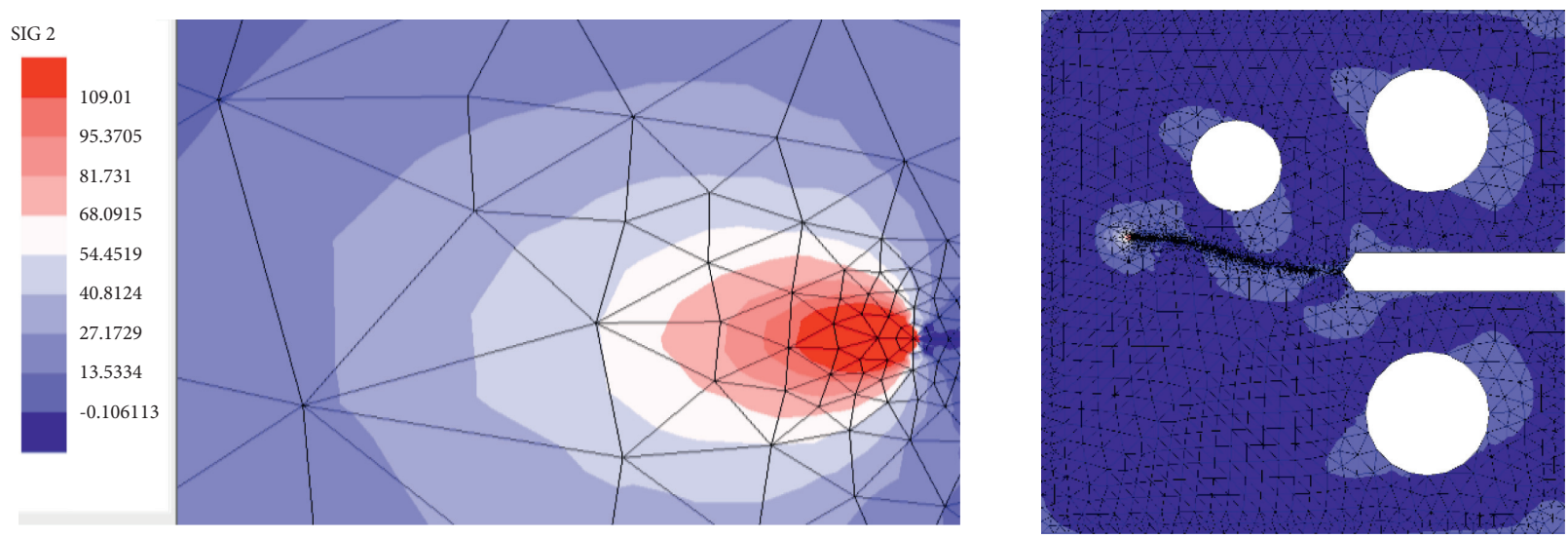

(c)

Figure 11: Continued. 

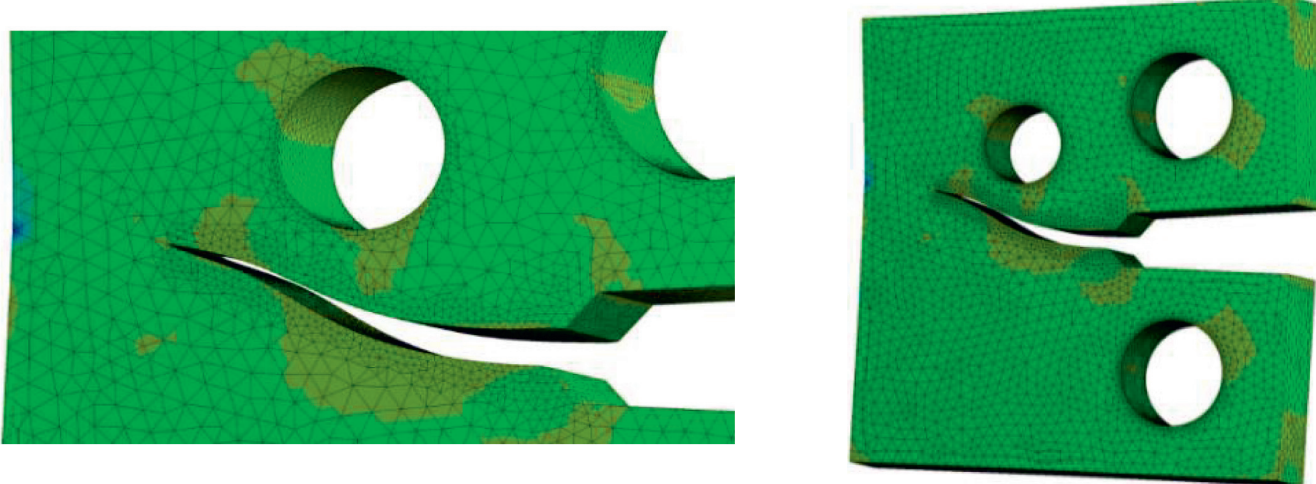

(d)

Figure 11: For CT03 specimen, (a) FRANC2D/L, maximum principal stress, (b) ANSYS, maximum principal stress, (c) FRANC2D/L, minimum principal stress, and (d) ANSYS, minimum principal stress.

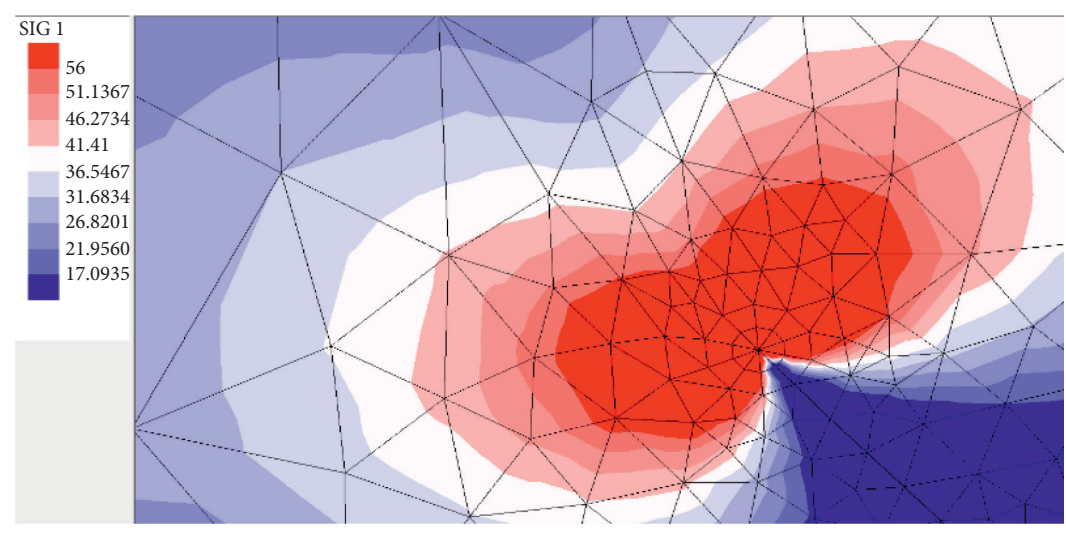

(a)
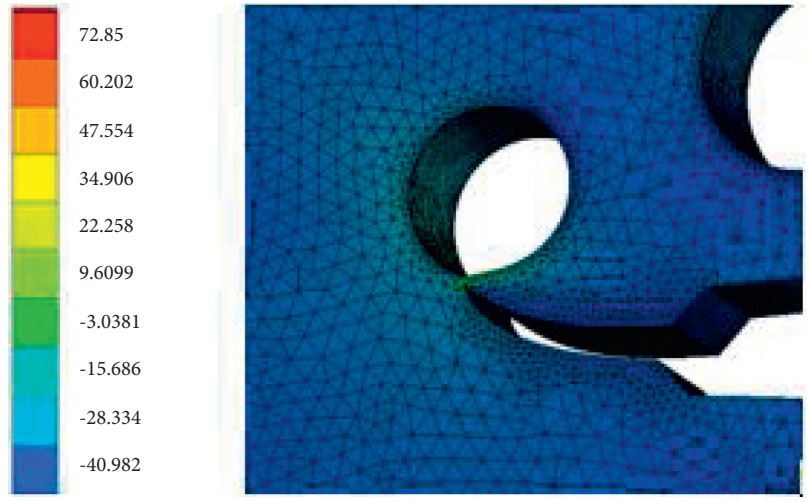

(b)
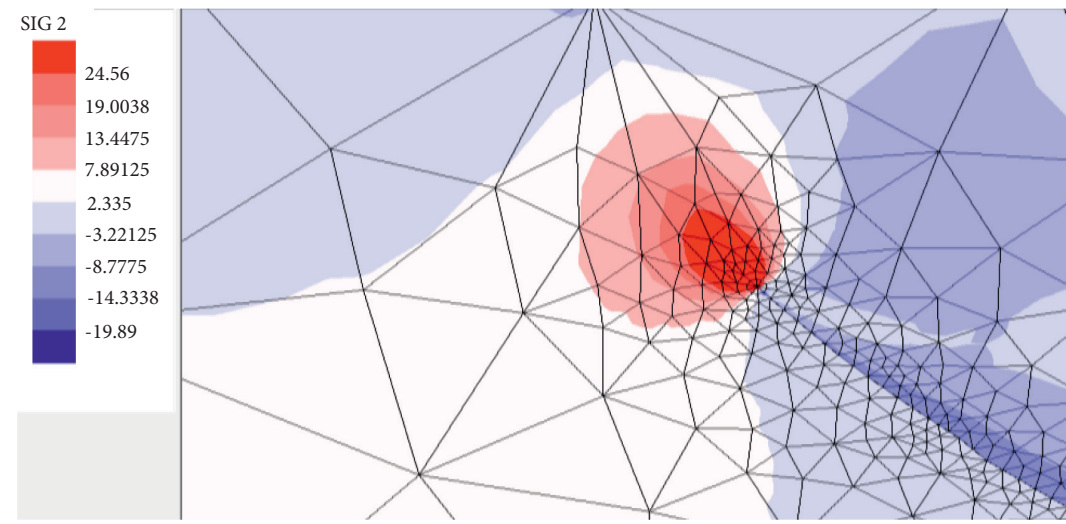

(c)

Figure 12: Continued.
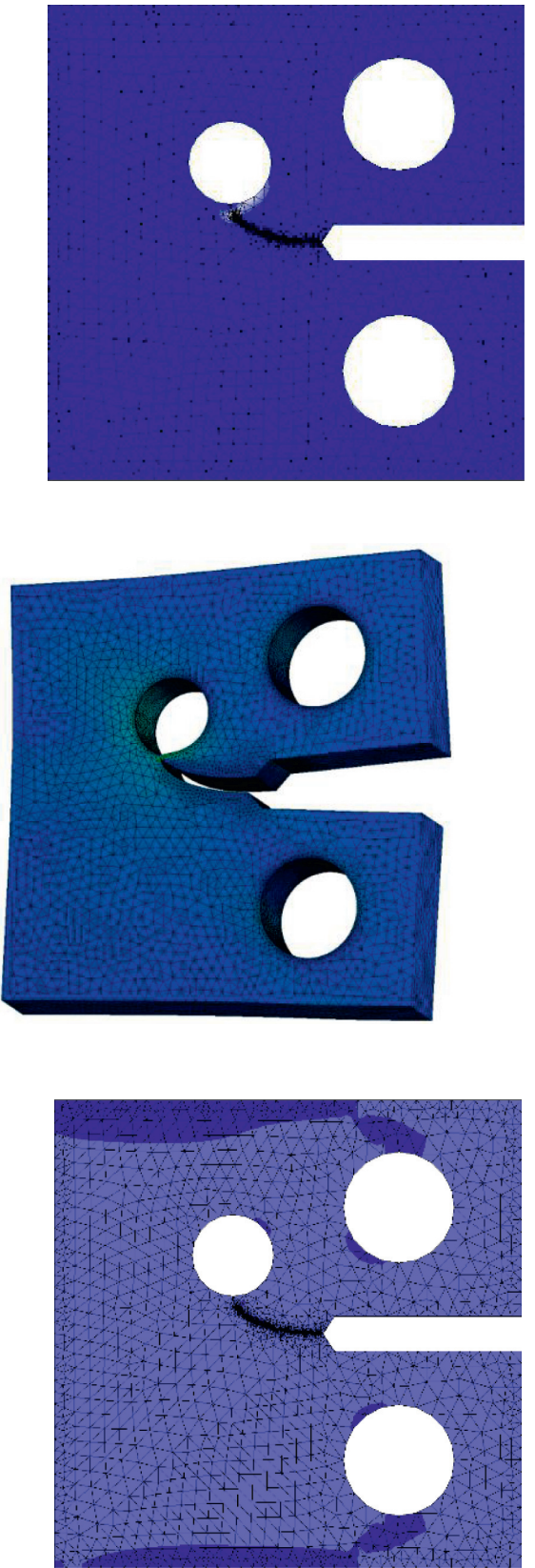

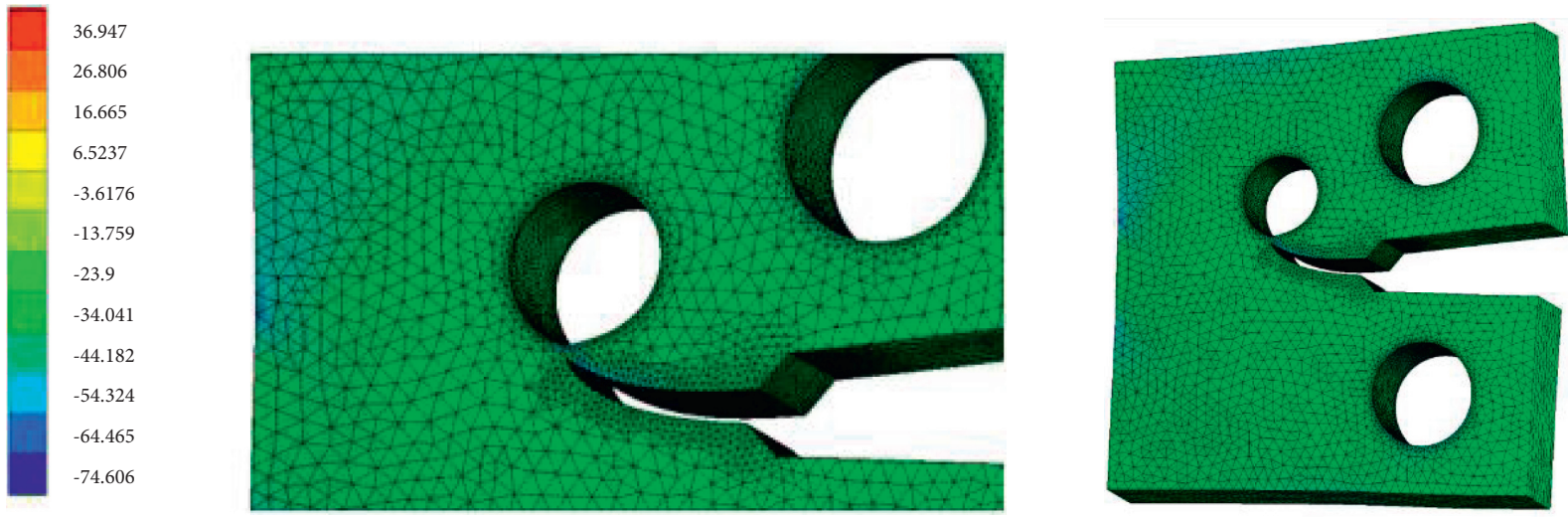

(d)

FIgURE 12: For CT04 specimen, (a) FRANC2D/L, maximum principal stress, (b) ANSYS, maximum principal stress, (c) FRANC2D/L, minimum principal stress, and (d) ANSYS, minimum principal stress.

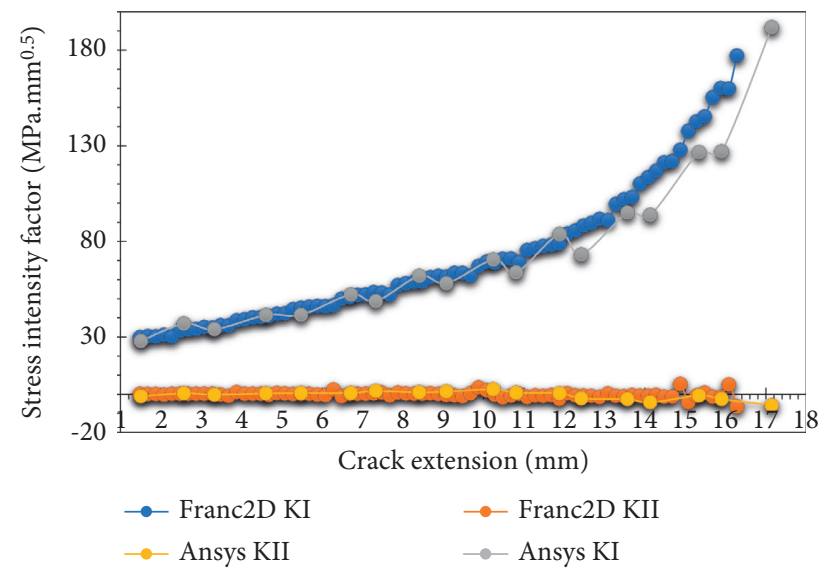

FIGURE 13: Stress intensity factors with corresponding crack length for CT01 specimen.

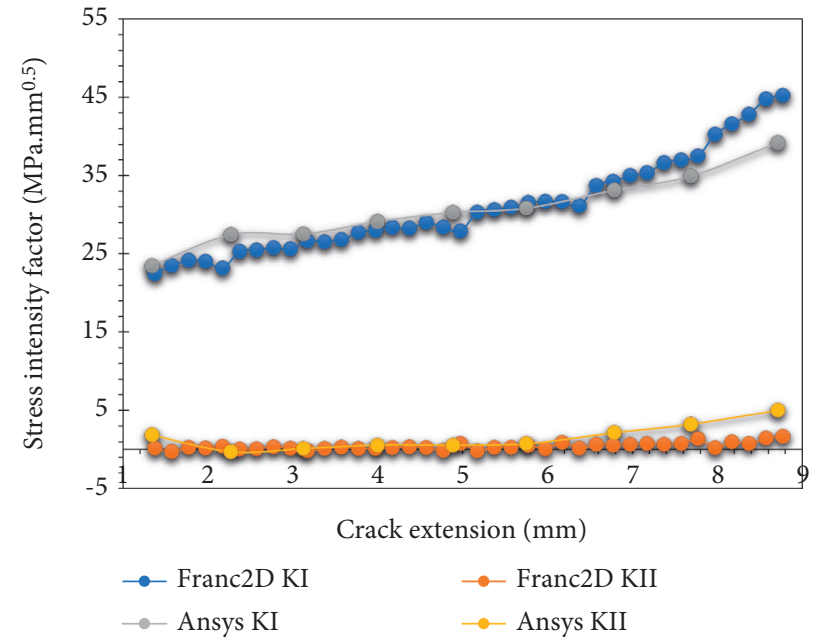

FIGURE 14: Stress intensity factors with corresponding crack length for CT02 specimen. 


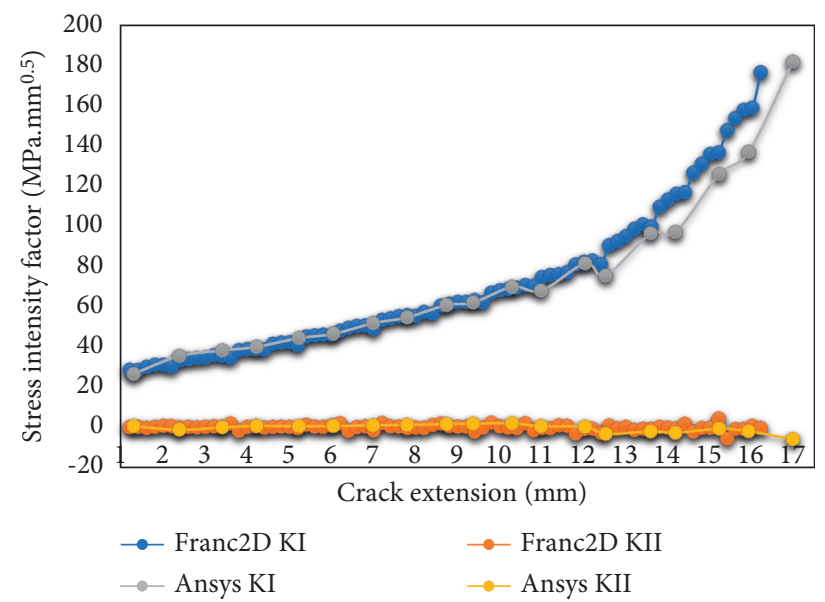

FIGURE 15: Stress intensity factors with corresponding crack length for CT03 specimen.

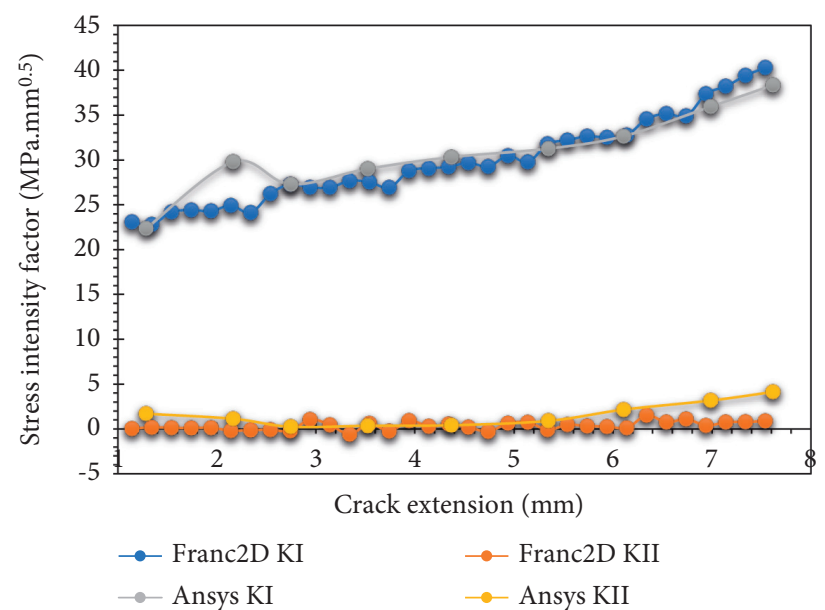

FIGURE 16: Stress intensity factors with corresponding crack length for CT04 specimen.

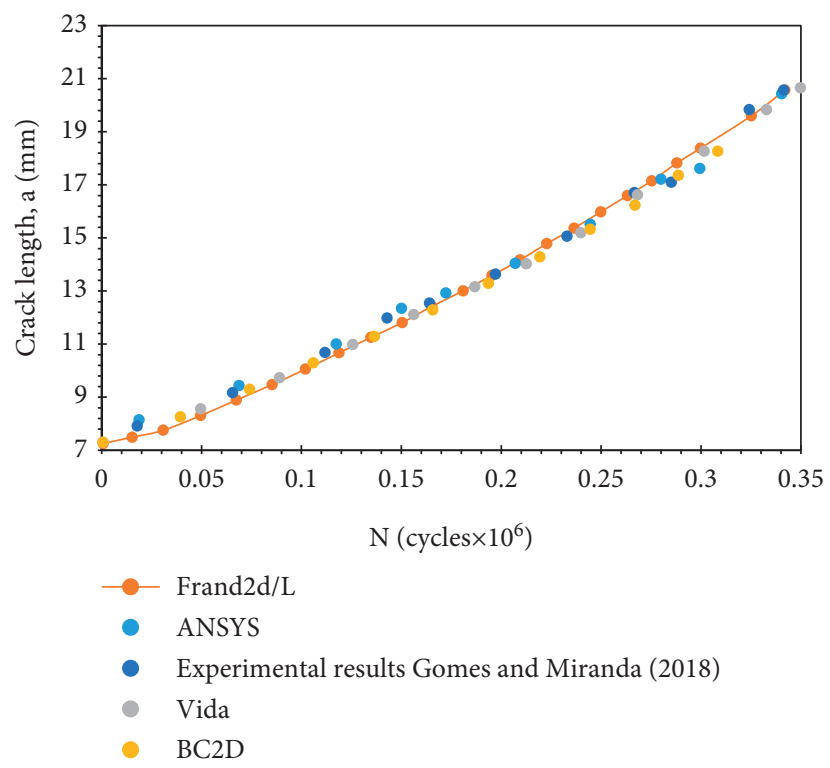

FIgUre 17: Comparison of the fatigue life and cracks length for the CTS01 specimen. 


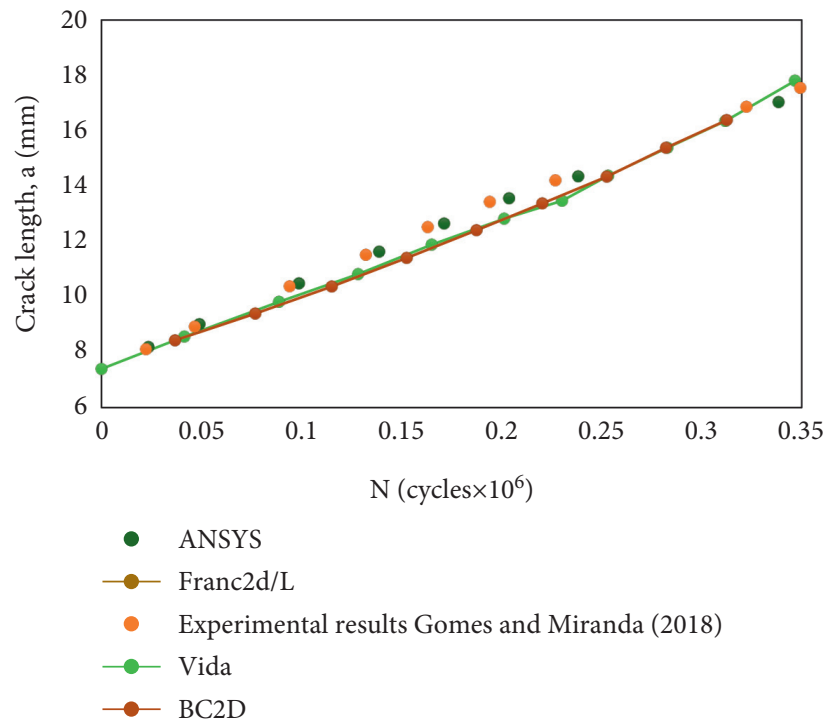

FIgURE 18: Comparison of the fatigue life and cracks length for the CTS02 specimen.

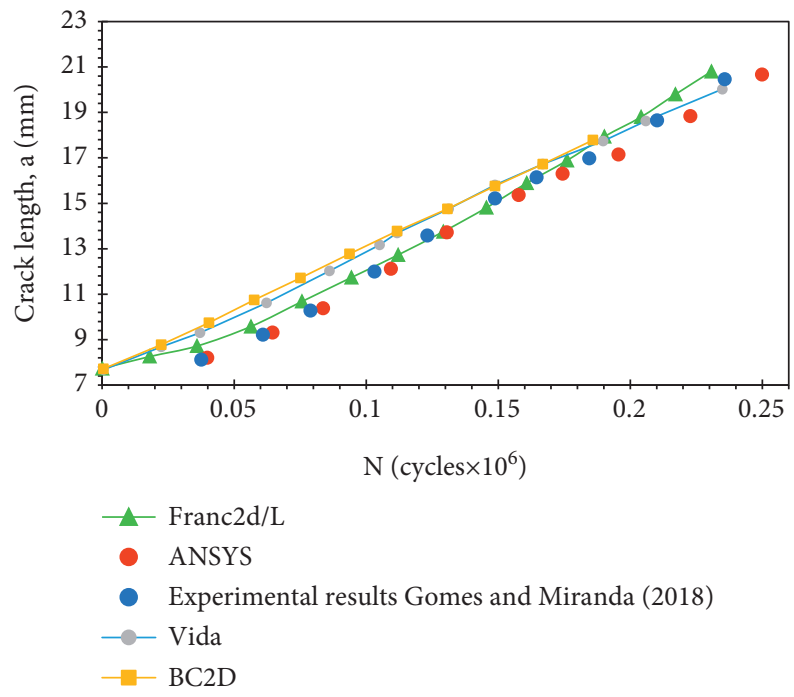

FIgure 19: Comparison of the fatigue life and cracks length for the CTS03 specimen.

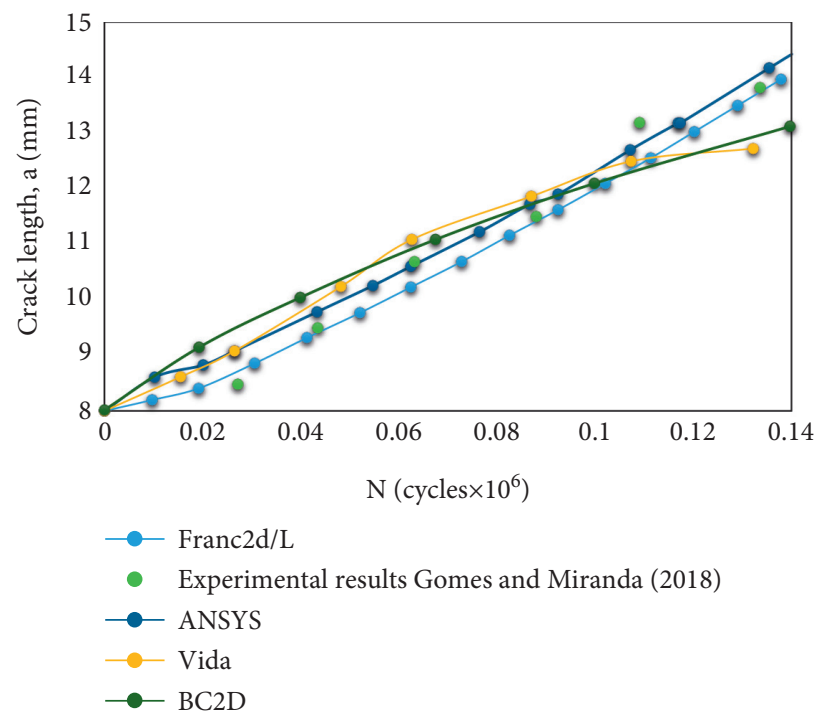

FIgURE 20: Comparison of the fatigue life and cracks length for the CTS04 specimen. 


\section{Conclusion}

According to the predicted results, the fatigue crack grows approach the hole due to the unequal stresses at the crack extremities as a result of the hole. Furthermore, different positions of the hole had a remarkable impact on the fatigue crack growth path. The crack direction bends more severely as the hole's core distance approaches the initial crack. The position of the hole influences the crack and modifies its path, either changing its pathway and growing into it or deviating from it and growing. The predicted fatigue crack growth paths, as well as the fatigue life cycles, were validated by the experimental and numerical findings performed by other researchers. Due to the available computing resources, the two-dimensional analysis offers a faster computational time than three-dimensional analysis while also allowing for a finer mesh to be generated on the geometry. In 3D models, the time increases dramatically as the mesh density increases. It is not always possible to simulate a complex geometry in $2 \mathrm{D}$, necessitating the use of $3 \mathrm{D}$ software. As a result, the $2 \mathrm{D}$ and $3 \mathrm{D}$ analytical results were nearly identical for plane stress geometries. For all geometries, the representations of stresses distribution in both software were visualized.

\section{Data Availability}

The data used to support this study are included within the article.

\section{Conflicts of Interest}

The author declares that there are no conflicts of interest.

\section{References}

[1] S. Suresh, Fatigue of Materials, Cambridge University Press, Cambridge, England, 1998.

[2] Z. Zhan, W. Hu, B. Li, Y. Zhang, Q. Meng, and Z. Guan, "Continuum damage mechanics combined with the extended finite element method for the total life prediction of a metallic component," International Journal of Mechanical Sciences, vol. 124-125, pp. 48-58, 2017.

[3] G. Sih and H. Liebowitz, "Mathematical fundamentals," in FractureVol. 2, Academic Press, New York, NY, USA, 1968.

[4] K. Hellan, Introduction to Fracture Mechanics, McGraw-Hill, 1985.

[5] J. Barsom and S. Rolfe, Fracture and Fatigue in Structure: Application of Fracture Mechanics, American Society for Testing and Materials Philadelphia, PA, US, 1999.

[6] D. Broek, Elementary Engineering Fracture Mechanics, Springer Science \& Business Media, Berlin/Heidelberg, Germany, 2012.

[7] P. C. Paris, H. Tada, and J. K. Donald, "Service load fatigue damage-a historical perspective," International Journal of Fatigue, vol. 21, pp. S35-S46, 1999.

[8] D. Bang, A. Ince, and M. Noban, "Modeling approach for a unified crack growth model in short and long fatigue crack regimes," International Journal of Fatigue, vol. 128, Article ID 105182, 2019.

[9] H. Dirik and T. Yalçinkaya, "Crack path and life prediction under mixed mode cyclic variable amplitude loading through
XFEM," International Journal of Fatigue, vol. 114, pp. 34-50, 2018.

[10] O. Demir, A. O. Ayhan, and S. İriç, "A new specimen for mixed mode-I/II fracture tests: modeling, experiments and criteria development," Engineering Fracture Mechanics, vol. 178, pp. 457-476, 2017.

[11] R. Zhang and R. Guo, "Determination of crack tip stress intensity factors by singular Voronoi cell finite element model," Engineering Fracture Mechanics, vol. 197, pp. 206216, 2018.

[12] P. O. Bouchard, F. Bay, Y. Chastel, and I. Tovena, "Crack propagation modelling using an advanced remeshing technique," Computer Methods in Applied Mechanics and Engineering, vol. 189, no. 3, pp. 723-742, 2000.

[13] Y.-S. Kim, S.-H. Yang, D. Shan, S.-O. Choi, S.-M. Lee, and B.-S. You, "Three-dimensional rigid-plastic FEM simulation of metal forming processes," Journal of Materials Engineering and Performance, vol. 15, no. 3, pp. 275-279, 2006.

[14] L. Duchêne, F. El Houdaigui, and A. M. Habraken, "Length changes and texture prediction during free end torsion test of copper bars with FEM and remeshing techniques," International Journal of Plasticity, vol. 23, pp. 1417-1438, 2007.

[15] A. M. P. d. Jesus, A. L. L. d. Silva, M. V. Figueiredo, J. A. F. O. Correia, A. S. Ribeiro, and A. A. Fernandes, "Strainlife and crack propagation fatigue data from several Portuguese old metallic riveted bridges," Engineering Failure Analysis, vol. 18, no. 1, pp. 148-163, 2011.

[16] X. Li, H. Li, L. Liu, Y. Liu, M. Ju, and J. Zhao, "Investigating the crack initiation and propagation mechanism in brittle rocks using grain-based finite-discrete element method," International Journal of Rock Mechanics and Mining Sciences, vol. 127, Article ID 104219, 2020.

[17] W. Leclerc, H. Haddad, and M. Guessasma, "On the suitability of a Discrete Element Method to simulate cracks initiation and propagation in heterogeneous media," International Journal of Solids and Structures, vol. 108, pp. 98-114, 2017.

[18] Y. Shao, Q. Duan, and S. Qiu, "Adaptive consistent elementfree Galerkin method for phase-field model of brittle fracture," Computational Mechanics, vol. 64, no. 3, pp. 741-767, 2019.

[19] S. A. Kanth, G. A. Harmain, and A. Jameel, "Modeling of nonlinear crack growth in steel and aluminum alloys by the element free Galerkin method," Materials Today Proceedings, vol. 5, no. 9, pp. 18805-18814, 2018.

[20] H. D. Huynh, M. N. Nguyen, G. Cusatis, S. Tanaka, and T. Q. Bui, "A polygonal XFEM with new numerical integration for linear elastic fracture mechanics," Engineering Fracture Mechanics, vol. 213, pp. 241-263, 2019.

[21] M. Surendran, S. Natarajan, G. S. Palani, and S. P. A. Bordas, "Linear smoothed extended finite element method for fatigue crack growth simulations," Engineering Fracture Mechanics, vol. 206, pp. 551-564, 2019.

[22] D. Rozumek, Z. Marciniak, G. Lesiuk, and J. A. F. O. Correia, "Mixed mode I/II/III fatigue crack growth in S355 steel," Procedia Structural Integrity, vol. 5, pp. 896-903, 2017.

[23] T. Belytschko and T. Black, "Elastic crack growth in finite elements with minimal remeshing," International Journal for Numerical Methods in Engineering, vol. 45, no. 5, pp. 601-620, 1999.

[24] R. Dekker, F. P. Meer, J. Maljaars, and L. J. Sluys, “A cohesive XFEM model for simulating fatigue crack growth under mixed-mode loading and overloading," International Journal for Numerical Methods in Engineering, vol. 118, no. 10, pp. 561-577, 2019. 
[25] S. Rezaei, S. Wulfinghoff, and S. Reese, "Prediction of fracture and damage in micro/nano coating systems using cohesive zone elements," International Journal of Solids and Structures, vol. 121, pp. 62-74, 2017.

[26] W. Zhang and A. Tabiei, "An efficient implementation of phase field method with explicit time integration," Journal of Applied and Computational Mechanics, vol. 6, pp. 373-382, 2020.

[27] A. M. Alshoaibi, "Finite element procedures for the numerical simulation of fatigue crack propagation under mixed mode loading," Structural Engineering \& Mechanics, vol. 35, no. 3, pp. 283-299, 2010.

[28] A. M. Alshoaibi, "Comprehensive comparisons of two and three dimensional numerical estimation of stress intensity factors and crack propagation in linear elastic analysis," International Journal of Integrated Engineering, vol. 11, pp. 45-52, 2019.

[29] A. M. Alshoaibi and Y. A. Fageehi, "2D finite element simulation of mixed mode fatigue crack propagation for CTS specimen," Journal of Materials Research and Technology, vol. 9, no. 4, pp. 7850-7861, 2020.

[30] Y. A. Fageehi and A. M. Alshoaibi, "Numerical simulation of mixed-mode fatigue crack growth for compact tension shear specimen," Advances in Materials Science and Engineering, vol. 2020, Article ID 5426831, 14 pages, 2020.

[31] H. Chen, Q. Wang, W. Zeng et al., "Dynamic brittle crack propagation modeling using singular edge-based smoothed finite element method with local mesh rezoning," European Journal of Mechanics-A: Solids, vol. 76, pp. 208-223, 2019.

[32] G. Gomes and A. C. O. Miranda, "Analysis of crack growth problems using the object-oriented program bemcracker2D," Frattura Ed Integrità Strutturale, vol. 12, no. 45, pp. 67-85, 2018.

[33] Y. A. Fageehi and A. M. Alshoaibi, "Nonplanar crack growth simulation of multiple cracks using finite element method," Advances in Materials Science and Engineering, vol. 2020, Article ID 8379695, 12 pages, 2020.

[34] H. Alizadeh, D. Hills, P. Dematos et al., "A comparison of two and three-dimensional analyses of fatigue crack closure," International Journal of Fatigue, vol. 29, no. 2, pp. 222-231, 2007.

[35] A. M. Alshoaibi and O. Yasin, "Finite element simulation of crack growth path and stress intensity factors evaluation in linear elastic materials," Journal of Computational and Applied Research in Mechanical Engineering, vol. 11, 2019.

[36] D. Rozumek and E. Macha, "Elastic-plastic fatigue crack growth in 18G2A steel under proportional bending with torsion loading," Fatigue and Fracture of Engineering Materials and Structures, vol. 29, no. 2, pp. 135-144, 2006.

[37] P. Paris and F. Erdogan, "A critical analysis of crack propagation laws," Journal of Basic Engineering, vol. 85, 1963.

[38] L. Coffin, Cyclic Deformation and Fatigue of metals. Fatigue and Endurance of Metals [Russian Translation], pp. 257-272, Elsevier, Moscow, Russia, 1963.

[39] A. Wöhler, "Versuche zur Ermittlung der auf die Eisenbahnwagenachsen einwirkenden Kräfte und die Widerstandsfähigkeit der Wagen-Achsen," Zeitschrift für Bauwesen, vol. 10, pp. 583-614, 1860.

[40] F. Bjørheim, Practical Comparison of Crack Meshing in ANSYS Mechanical APDL 19.2, University of Stavanger, Norway, 2019.

[41] inANSYS. Academic Research Mechanical, Release 19.2ANSYS, Inc., Bengaluru, India, 2020.
[42] T. Kebir, M. Benguediab, and A. Imad, "A model for fatigue crack growth in the paris regime under the variability of cyclic hardening and elastic properties," Fatigue of Aircraft Structures, vol. 2017, 2017.

[43] V. M. Radhakrishnan, "Quantifying the parameters in fatigue crack propagation,” Engineering Fracture Mechanics, vol. 13, no. 1, pp. 129-141, 1980.

[44] L. Tóth and A. J. Krasowsky, "Fracture as the result of selforganised damage process," Journal of Materials Processing Technology, vol. 53, pp. 441-451, 1995.

[45] F. Iacoviello, D. Iacoviello, and M. Cavallini, "Analysis of stress ratio effects on fatigue propagation in a sintered duplex steel by experimentation and artificial neural network approaches," International Journal of Fatigue, vol. 26, no. 8, pp. 819-828, 2004.

[46] J. Petit, J. De Fouquet, G. Henaff, and A. Carpenteri, Handbook of Fatigue Crack Propagation in Metallic Structures, Sciencedirect, Carpinteri A, California, pp. 1159-1203, 1994.

[47] Y. Xiangqiao, D. Shanyi, and Z. Zehua, "Mixed-mode fatigue crack growth prediction in biaxially stretched sheets," Engineering Fracture Mechanics, vol. 43, no. 3, pp. 471-475, 1992.

[48] P. Kumar, M. E. Makhatha, S. Sengupta, and A. K. Dutt, Prediction of the Propagation of Fatigue Cracks in PartThrough Cracked Pipes with CASCA and FRANC2D, pp. 1-4, Transactions of the Indian Institute of Metals, India, 2020.

[49] A. Ahola, T. Björk, and Z. Barsoum, "Fatigue strength capacity of load-carrying fillet welds on ultra-high-strength steel plates subjected to out-of-plane bending," Engineering Structures, vol. 196, Article ID 109282, 2019.

[50] A. C. O. Miranda, M. A. Meggiolaro, J. T. P. Castro, L. F. Martha, and T. N. Bittencourt, "Fatigue life and crack path predictions in generic 2D structural components," Engineering Fracture Mechanics, vol. 70, no. 10, pp. 1259-1279, 2003. 